NBER WORKING PAPER SERIES

\title{
RISK AVERSION AND WEALTH: EVIDENCE FROM PERSON-TO-PERSON LENDING PORTFOLIOS
}

\author{
Daniel Paravisini \\ Veronica Rappoport \\ Enrichetta Ravina \\ Working Paper 16063 \\ http://www.nber.org/papers/w16063
}

\author{
NATIONAL BUREAU OF ECONOMIC RESEARCH \\ 1050 Massachusetts Avenue \\ Cambridge, MA 02138 \\ June 2010
}

We are grateful to Lending Club for providing the data and for helpful discussions on this project. We thank Michael Adler, Manuel Arellano, Nick Barberis, Geert Bekaert, Patrick Bolton, John Campbell, Larry Glosten, Nagpurnanand Prabhala, Bernard Salanie, and seminar participants at CEMFI, Columbia University GSB, Duke Fuqua School of Business, Hebrew University, Harvard Business School, Kellogg School of Management, Kellstadt Graduate School of Business-DePaul, London Business School, Maryland Smith School of Business, M.I.T. Sloan, Universidad Nova de Lisboa, the Yale 2010 Behavioral Science Conference, and the SED 2010 meeting for helpful comments. All remaining errors are our own. The views expressed herein are those of the authors and do not necessarily reflect the views of the National Bureau of Economic Research.

NBER working papers are circulated for discussion and comment purposes. They have not been peerreviewed or been subject to the review by the NBER Board of Directors that accompanies official NBER publications.

(C) 2010 by Daniel Paravisini, Veronica Rappoport, and Enrichetta Ravina. All rights reserved. Short sections of text, not to exceed two paragraphs, may be quoted without explicit permission provided that full credit, including (C) notice, is given to the source. 
Risk Aversion and Wealth: Evidence from Person-to-Person Lending Portfolios

Daniel Paravisini, Veronica Rappoport, and Enrichetta Ravina

NBER Working Paper No. 16063

June 2010, Revised April 2011

JEL No. D12,D14,E21,G11

\begin{abstract}
$\underline{\text { ABSTRACT }}$
We estimate risk aversion from the actual financial decisions of 2,168 investors in Lending Club (LC), a person-to-person lending platform. We develop a methodology that allows us to estimate risk aversion parameters from each portfolio choice. Since the same individual makes repeated investments, we are able to construct a panel of risk aversion parameters that we use to disentangle heterogeneity in attitudes towards risk from the elasticity of investor-specific risk aversion to changes in wealth. In the cross section, we find that wealthier investors are more risk averse. Using changes in house prices as a source of variation, we find that investors become more risk averse after a negative wealth shock. These preferences consistently extrapolate to other investor decisions within LC.
\end{abstract}

Daniel Paravisini

Columbia University

Graduate School of Business

3022 Broadway, Uris Hall 416

New York, NY 10027

and NBER

dp2239@columbia.edu

Veronica Rappoport

Finance \& Economics Division

Columbia Business School

3022 Broadway, Uris Hall 821

New York, NY 10027

ver2102@columbia.edu
Enrichetta Ravina

Columbia University

Finance and Economics Division

Uris Hall

3022 Broadway

New York, NY, 10027

er2463@columbia.edu 


\section{Introduction}

Theoretical predictions on investment, asset prices, and the cost of business cycles, depend crucially on assumptions about the relationship between risk aversion and wealth 11 Although characterizing this relationship has long been in the research agenda of empirical finance and economics, progress has been hindered by the difficulty of disentangling the shape of the utility function from preference heterogeneity across agents and changes in beliefs over time. For example, the bulk of existing work is based on comparisons of risk aversion across investors of different wealth, which requires assuming that agents have the same preference function. If agents have heterogeneous preferences, however, cross sectional analysis leads to incorrect inferences about the shape of the utility function when wealth and preferences are correlated. Such a correlation may arise, for example, if agents with heterogenous propensity to take risk make different investment choices, which in turn affect their wealth ${ }^{2}$ To both characterize the properties of the joint distribution of preferences and wealth in the cross section, and estimate the parameters describing the utility function, one needs to observe how the risk aversion of the same individual changes with wealth shocks.

Important recent work improves on the cross-sectional approach by looking at changes in the fraction of risky assets in an investor's portfolio that stem from the time series variation in investor wealth (Brunnermeier and Nagel (2008) and Calvet, Campbell and Sodini (2009)). The crucial identifying assumption required for using the share of risky assets as a proxy for investor Relative Risk Aversion (RRA) in this setting, is that all other determinants of the share of risky assets remain constant as the investor's wealth changes. One must assume, for example, that changes in investors' beliefs about the expected return of risky assets, or about the returns

\footnotetext{
${ }^{1}$ See Kocherlakota (1996) for a discussion of the literature aiming at resolving the equity premium and low risk free rate puzzles under different preference assumptions. Campbell and Cochrane (1999), for example, model preferences with habit formation that produce cyclical variations in risk aversion, and decreasing relative risk aversion after a positive wealth shock. Gollier (2001) shows that wealth inequality raises the equity premium if the absolute risk aversion is concave in wealth.

${ }^{2}$ Guvenen (2009) and Gomes and Michaelides (2008) propose a model with preference heterogeneity that endogenously generates cross sectional variation in wealth. Alternatively, an unobserved investor characteristic, such as having more educated parents, may jointly affect wealth and the propensity to take risk.
} 
of unobservable components of wealth such as human capital, are uncorrelated with shocks to financial wealth. Attempts to address this identification problem through an instrumental variable approach have produced mixed results: the estimated sign of the elasticity of RRA to wealth varies across studies depending on the choice of instrument 3

The present paper exploits a novel environment to obtain unbiased measures of investor risk aversion and relate them to investor wealth. We analyze the risk taking behavior of 2,168 investors based on their actual financial decisions in Lending Club (LC), a person-to-person lending platform in which individuals invest in diversified portfolios of small loans. We develop a methodology to estimate the local curvature of an investor's utility function (Absolute Risk Aversion, or ARA) from each portfolio choice. The key advantage of this estimation approach is that it does not require characterizing investors' outside wealth. We exploit the fact that the same individuals make repeated investments in LC to construct a panel of risk aversion estimates. We use this panel to both characterize the cross sectional correlation between risk preferences and wealth, and to obtain reduced form estimates of the elasticity of investor-specific risk aversion to changes in wealth.

Our estimation method is derived from an optimal portfolio model where investors not only hold the market portfolio, but also securities for which they have subjective insights (Treynor and Black (1973)). We treat investments in LC as special-insight securities, with returns that are correlated with other securities through a common systematic factor (Sharpe's Diagonal Model). This implies that LC returns can be decomposed into a systematic component, correlated with macroeconomic fluctuations, and a pure idiosyncratic component. We use the idiosyncratic component to characterize investors' preferences: an investor's ARA is given by the additional expected return that makes her indifferent about allocating the marginal dollar to a loan with higher idiosyncratic default probability. Estimating risk preferences from the idiosyncratic component of returns implies that the estimates are independent from the investors' overall risk exposure or wealth. Moreover, by measuring the curvature of the utility function directly from

\footnotetext{
${ }^{3}$ See Calvet et al. (2009) and Calvet and Sodini (2009) for a discussion.
} 
the first order condition of this portfolio choice problem, we do not need to impose a specific shape of the utility function. We show that our method obtains consistent estimates for the curvature of the utility function under alternative preference specifications, such as expected utility (EU) over wealth, EU over wealth and income, loss aversion, and narrow framing.

The average ARA implied by the tradeoff between expected return and idiosyncratic risk in our sample of portfolio choices is 0.037. Our estimates imply an average income-based Relative Risk Aversion (income-based RRA), a commonly reported risk preference parameter in experimental studies obtained assuming that the investor's outside wealth is zero, of 2.85 , with substantial unexplained heterogeneity and skewness 4 We use experimental measurements of risk aversion to benchmark our estimates because investors in our model face choices that are similar to those faced by typical experimental subjects along important dimensions: Our model transforms a complex portfolio choice problem into a choice between well defined lotteries of pure idiosyncratic risk, where returns are characterized by a discrete failure probability (i.e., default) and the stakes are small relative to total wealth (the median investment in LC is $\$ 375$ ). The level, distribution, and skewness of the estimated risk aversion parameters are similar to those obtained in laboratory and field experiments.5 These similarities indicate that investors in our sample, despite being a self selected sample of individuals who invest on-line, have similar risk preferences to individuals in other settings.

Using imputed net worth as a proxy for wealth in the cross section of investors, we find that wealthier investors exhibit lower ARA and higher RRA when choosing LC loan portfolios $6^{6}$ Our preferred specification, which corrects for measurement error in the wealth proxy using house prices in the investor's zip code as an instrument, obtains an elasticity of ARA to wealth of -0.059, which implies a cross sectional wealth elasticity of the RRA of 0.94 .7

\footnotetext{
${ }^{4}$ The income-based RRA, often reported in the experimental literature, is defined as $A R A \cdot E[y]$, where $E[y]$ is the expected income from the lottery offered in the experiment.

${ }^{5}$ See for example Barsky, Juster, Kimball and Shapiro (1997), Holt and Laury (2002), Choi, Fisman, Gale and Kariv (2007), and Harrison, Lau and Rutstrom (2007b).

${ }^{6}$ Net worth is imputed by Acxiom as of October 2007. Acxiom is a third party specialized in recovering consumer demographics based on public data.

${ }^{7}$ Although the wealth-based RRA is not directly observable, we compute its elasticity from the following relationship: $\xi_{R R A, W}=\xi_{A R A, W}+1$,where $\xi_{R R A, W}$ and $\xi_{A R A, W}$ refer to the wealth elasticities of RRA and ARA,
} 
The results demonstrate that there is a link between heterogeneity in risk preferences and wealth in the cross section. Existing empirical evidence on this link, which is increasingly relevant for modeling asset prices, is inconclusive. When the risk aversion parameters are estimated from the share of risky and riskless assets, the sign of the correlation between risk aversion and wealth is sensitive to the definition of wealth and the categorization of assets into risky and riskless (see, among others, Blume and Friend (1975), Cohn, Lewellen, Lease and Schlarbaum (1975), Morin and Suarez (1983), and Blake (1996)). Guiso and Paiella (2008) and Cicchetti and Dubin (1994) avoid this problem by estimating risk aversion from answers to an hypothetical lottery and data on insurance against phone line troubles, respectively. These studies find, as we do, a positive cross sectional correlation between Relative Risk Aversion and wealth.

To characterize the shape of the utility function for the average investor, we estimate the elasticity of risk aversion to changes in wealth in an investor fixed-effect specification. As a wealth shock, we use the decline in house prices in the investor's zip code during our sample period-October 2007 to April 2008. The results indicate that the average investor's RRA increases after experiencing a negative housing wealth shock, with an estimated elasticity of -1.82. Under reasonable assumptions about the relationship between housing and total wealth during this period, the point estimates imply that the curvature of the value function increases after a negative wealth shock. This is consistent with investors exhibiting decreasing Relative Risk Aversion, and with theories of habit formation (as in Campbell and Cochrane (1999)), and incomplete markets (as in Guvenen (2009)) 8

A novel feature of our estimation approach is that it disentangles the measurement of risk aversion from investors' assessments about the systematic risk of LC loans. On average, the LC systematic risk premium increases from $6.3 \%$ to $9.2 \%$ between the first and last three months of the sample, indicating that investors' priors on LC's systematic risk increase substantially during the period.

respectively.

${ }^{8}$ These preference specifications are also consistent with the empirical findings in Calvet et al. (2009). Brunnermeier and Nagel (2008), on the other hand, find support for CRRA. 
Overall, the results confirm that not accounting for preference heterogeneity and changes in beliefs may bias estimates of the relationship between risk preferences and wealth. First, the contrasting signs of the cross sectional and investor-specific wealth elasticities indicate that inference on the elasticity of risk aversion to wealth from cross sectional data will be biased, since risk taking behavior in the cross section of investors depends not only on the shape of the utility function but also on the joint distribution of preferences and wealth 9 Second, our finding that the expected return on LC systematic risk increases after house prices decline indicates that wealth shocks are potentially correlated with general changes in investors' beliefs. This implies that the share of risky assets may not be a valid measure for investor RRA in the presence of wealth shocks. In our context, for example, inference based on the share of risky assets alone would have overestimated the elasticity of risk aversion to wealth.

The LC environment allows us to test for estimation bias due to misspecification of investors' beliefs. An investor in LC can choose her investment portfolio manually or through an optimization tool. When the choice is manual, she selects loans by processing herself the information on interest and idiosyncratic default rates provided on LC's website. When she uses the tool, the tool processes this information for her, by providing all the possible efficient (minimum variance) portfolios that can be constructed with the available loans. The investor then chooses among the efficient portfolios according to her own risk preferences. Importantly, our estimation procedure and the tool use the same information on risk and return, and the same modeling assumptions regarding a common systematic component across all potential loans. Any bias due to misspecified beliefs will result in a wedge between the risk aversion estimates based on manual and automatic choices. Instead, we obtain the same risk aversion estimates when investors choose portfolios manually or through the tool, which validates our modeling assumption.

We provide additional validity to our estimates by testing whether the level and wealth

\footnotetext{
${ }^{9}$ Chiappori and Paiella (2008) find the bias from the cross sectional estimation to be economically insignificant. In their case, however, changes in agent's wealth are not exogenous, and risk aversion is measured through the share of risky assets. Tanaka, Camerer and Nguyen (2010) use rainfall across villages in Vietnam as an instrument for wealth and find significant difference between the OLS and IV estimators. However, to obtain the elasticity of the agent-specific risk aversion, they must assume that preferences are equal across villages otherwise.
} 
elasticity of risk aversion are consistent across different investors' decisions within LC. We test the consistency of the estimated level of risk aversion using a revealed preference argument. The median investor has in her portfolio only a subset of the loans available at the time of her investment decision. We use the foregone loans to perform an out-of-sample validation of the ARA estimate obtained from the loans in the portfolio. We confirm that including the foregone loans in the portfolio would lower the investor's expected utility if her preferences are described by the estimated ARA.

We also verify the consistency of the estimated elasticities of RRA to wealth by testing the following predictions of the standard EU framework: when relative risk aversion decreases (increases) in outside wealth, the share of wealth invested in LC will increase (decrease) in outside wealth. Since our risk aversion measures are obtained solely from the composition of each investment, these predictions can be tested out of sample by independently estimating the elasticity of the total amount invested in LC to wealth. We find that the implied signs of the RRA and total investment elasticities, both in the cross section and within investor, are consistent with the predictions above.

The rest of the paper is organized as follows. Section 2 describes the Lending Club platform. Section 3 solves the portfolio choice model and sets out our estimation strategy. Section 4 describes the data and the sample restrictions. Section 5 presents and discusses the empirical results and provides a test of the identification assumptions. Section 6 explores the relationship between risk preferences and wealth. Section 7 tests the consistency of the investor preferences across different decisions within LC. And Section 8 concludes.

\section{The Lending Platform}

Lending Club (LC) is an online U.S. lending platform that allows individuals to invest in portfolios of small loans. The platform started operating in June 2007. As of May 2010, it has funded $\$ 112,003,250$ in loans and provided an average net annualized return of $9.64 \%$ to investors 10

\footnotetext{
${ }^{10}$ For the latest figures refer to: https://www.lendingclub.com/info/statistics.action.
} 
Below, we provide an overview of the platform and derive the expected return and variance of investors' portfolio choices.

\section{$2.1 \quad$ Overview}

Borrowers need a U.S. SSN and a FICO score of 640 or higher in order to apply. They can request a sum ranging from $\$ 1,000$ to $\$ 25,000$, usually to consolidate credit card debt, finance a small business, or fund educational expenses, home improvements, or the purchase of a car.

Each application is classified into one of 35 risk buckets based on the FICO score, the requested loan amount, the number of recent credit inquiries, the length of the credit history, the total and currently open credit accounts, and the revolving credit utilization, according to a pre-specified published rule posted on the website 11 LC also posts a default rate for each risk bucket, taken from a long term validation study by TransUnion, based on U.S. unsecured consumer loans. All the loans classified in a given bucket offer the same interest rate, assigned by LC based on an internal rule.

A loan application is posted on the website for a maximum of 14 days. It becomes a loan only if it attracts enough investors and gets fully funded. All the loans have a 3 year term with fixed interest rates and equal monthly installments, and can be prepaid with no penalty for the borrower. When the loan is granted, the borrower pays a one-time fee to LC ranging from $1.25 \%$ to $3.75 \%$, depending on the credit bucket. When a loan repayment is more than 15 days late, the borrower is charged a late fee that is passed to investors. Loans with repayments more than 120 days late are considered in default, and LC begins the collection procedure. If collection is successful, investors receive the amount repaid minus a collection fee that varies depending on the age of the loan and the circumstances of the collection. Borrower descriptive statistics are shown in Table 1, panel A.

Investors in LC allocate funds to open loan applications. The minimum investment in a loan is $\$ 25$. According to a survey of 1,103 LC investors in March 2009, diversification and high

\footnotetext{
${ }^{11}$ Please refer to https://www.lendingclub.com/info/how-we-set-interest-rates.action for the details of the classification rule and for an example.
} 
returns relative to alternative investment opportunities are the main motivations for investing in LC ${ }^{12}$ LC lowers the cost of investment diversification inside LC by providing an optimization tool that constructs the set of efficient loan portfolios for the investor's overall amount invested in LC - i.e., the minimum idiosyncratic variance for each level of expected return (see Figure 1 ) 13 In other words, the tool helps investors to process the information on interest rates and default probabilities posted on the website into measures of expected return and idiosyncratic variance, that may otherwise be difficult to compute for an average investor (these computations are performed in Subsection 2.2) 14 When investors use the tool, they select, among all the efficient portfolios, the preferred one according to their own risk preferences. Investors can also use the tool's recommendation as a starting point and then make changes. Or they can simply select the loans in their portfolio manually.

Of all portfolio allocations between LC's inception and June 2009, 39.6\% was suggested by the optimization tool, $47.1 \%$ was initially suggested by the tool and then altered by the investor, and the remaining $13.3 \%$ was chosen manually.15

Given two loans that belong to the same risk bucket (with the same idiosyncratic risk), the optimization tool suggests the one with the highest fraction of the requested amount that is already funded. This tie-breaking rule maximizes the likelihood that loans chosen by investors are fully funded. In addition, if a loan is partially funded at the time the application expires, LC provides the remaining funds.

\footnotetext{
${ }^{12}$ To the question "What would you say was the main reason why you joined Lending Club", $20 \%$ of respondents replied "to diversify my investments", $54 \%$ replied "to earn a better return than (...)", $16 \%$ replied "to learn more about peer lending", and 5\% replied "to help others". In addition, $62 \%$ of respondents also chose diversification and higher returns as their secondary reason for joining Lending Club.

${ }^{13}$ During the period analyzed in this paper, the portfolio tool appeared as the first page to the investors. LC has recently changed its interface and, before the portfolio tool page, it has added a stage where the lender can simply pick between 3 representative portfolios of different risk and return.

${ }^{14}$ The tool normalizes the idiosyncratic variance into a $1-0$ scale. Thus, while the tool provides an intuitive sorting of efficient portfolios in terms of their idiosyncratic risk, investors always need to analyze the recommended portfolios of loans to understand the actual risk level imbedded in the suggestion.

${ }^{15}$ We exploit this variation in Subsection 5.2 to validate the identification assumptions.
} 


\subsection{Return and Variance of the Risk Buckets}

All the loans in a given risk bucket $z=1, \ldots, 35$ are characterized by the same scheduled monthly payment per dollar borrowed, $P_{z}$, over the 3 years (36 monthly installments). The per dollar scheduled payment $P_{z}$ and the bucket specific default rate $\pi_{z}$ fully characterize the expected return and variance of per project investments, $\mu_{z}$ and $\sigma_{z}^{2}$.

LC considers a geometric distribution for the idiosyncratic monthly survival probability of the individual projects, $\operatorname{Pr}(T=\tau)=\pi_{z}\left(1-\pi_{z}\right)^{\tau}$ for $T \in[1,36]$. The resulting expectation and variance of the present value of the payments, $P_{z}$, of a project in bucket $z$ are:

$$
\begin{aligned}
\mu_{z} & =P_{z}\left[1-\left(\frac{1-\pi_{z}}{1+r}\right)^{36}\right] \frac{1-\pi_{z}}{r+\pi_{z}} \\
\sigma_{z}^{2} & =\sum_{t=1}^{35} \pi_{z}\left(1-\pi_{z}\right)^{t}\left(\sum_{\tau=1}^{t} \frac{P_{z}}{(1+r)^{\tau}}\right)^{2}+\left(\sum_{\tau=1}^{36} \frac{P_{z}}{(1+r)^{\tau}}\right)^{2}\left(1-\pi_{z}\right)^{36}-\mu_{z}^{2}
\end{aligned}
$$

where $r$ is the risk-free interest rate. Although LC considers all risk to be idiosyncratic, our estimations are not affected by the introduction of a non-diversifiable risk component, $V_{z}$. The resulting variance of the return on investment in bucket $z$ is given by:

$$
\operatorname{var}\left[R_{z}^{i}\right]=V_{z}+\operatorname{var}\left[r_{z}^{i}\right]
$$

where $r_{z}^{i}$ is the idiosyncratic component of the bucket's return $R_{z}^{i}$.

The idiosyncratic risk associated with bucket $z$ decreases with the level of diversification within the bucket; that is, the number of projects from bucket $z$ in the portfolio of investor $i$, $n_{z}^{i}$. The resulting idiosyncratic variance is therefore investor specific:

$$
\operatorname{var}\left[r_{z}^{i}\right]=\frac{1}{n_{z}^{i}} \sigma_{z}^{2}
$$

The expected return of an investment in bucket $z$ is not affected by the number of loans in the investor's portfolio and is equal to the expected return of the representative project in that 
bucket, $\mu_{z}$, which is constant across investors 16

$$
E\left[R_{z}\right]=E\left[R_{z}^{i}\right]=\mu_{z}
$$

\section{Estimation Procedure}

The portfolio model in this section is based on Treynor and Black (1973). This framework considers investors that, instead of simply holding a replica of the market portfolio, also hold securities based on their own subjective insights.

Person-to-person lending markets, including LC, are not well known investment vehicles among the general public. The decision to invest in LC depends on investors' knowledge of its existence and their subjective expectation that LC is, indeed, a good investment opportunity. Thus, it is reasonable to assume that investors in LC have special insights, which explains why, as we show later, their portfolio departs from just replicating the market; exactly the case considered in Treynor and Black (1973).

This theoretical framework starts by recognizing that there is a high degree of co-movement between securities, and specifically to our case, the probability of default of all loans in LC is potentially correlated with macroeconomic fluctuations. We use Shape's Diagonal Model of covariance among securities to capture this insight. It assumes that returns are related only through a common systematic factor (i.e., market or macroeconomic fluctuations). Under this assumption, returns on LC loans can be decomposed into this common systematic factor and a pure idiosyncratic component (we also refer to it as independent return).

The virtue of the model developed here is that the optimal portfolio depends only on the expected return and variance of the idiosyncratic component. In other words, the optimal amount invested in each LC loan does not depend on the return covariance with the investor's overall risk exposure, nor does it require knowing the amount and characteristics of her outside

\footnotetext{
${ }^{16}$ The analysis in subsection 5.2 confirms that investors' beliefs about the probabilities of default do not differ substantially from those posted on the website and, therefore, $\sigma_{z}$ and $\mu_{z}$ are constant across investors.
} 
wealth. The optimality condition is such that the investor is indifferent about allocating an extra dollar in a riskier bucket: the extra idiosyncratic risk would be exactly compensated by the increase in expected return, given the risk aversion of the investor. Based on this optimality condition, and having computed the expected return and the variance of the loans idiosyncratic risk in Subsection 2.2, we infer the investor specific risk aversion.

\subsection{The Model}

Each investor $i$ chooses the share of wealth to be invested in the $Z+2$ available securities: a security $m$ that represents the market portfolio, with return $R_{m}$; a security $f$, with risk-free return equal to 1 ; and $Z$ securities that are part of the active portfolio of the investor, with return $R_{z}$.

We consider investments in LC as part of the active portfolio. We also allow for the existence of unobservable outside active risky investments. That is, the 35 risk buckets in LC are denote $z=1, \ldots, 35$, with $35 \leq Z{ }^{17}$ The resulting portfolio of investor $i$ is

$$
c^{i}=W^{i}\left[x_{f}^{i}+x_{m}^{i} R_{m}+\sum_{z=1}^{Z} x_{z}^{i} R_{z}^{i}\right]
$$

where $c^{i}$ stands for the investor's consumption and $x_{f}, x_{m}$, and $\left\{x_{z}\right\}_{z=1}^{Z}$ correspond to the share of wealth, $W^{i}$, invested in the risk-free asset, the market portfolio, and the securities in the active portfolio, respectively.

A projection of the return of each active security $z=1, \ldots, Z$ against the market gives two factors. The first is the market sensitivity, or beta, of the security, and the second its independent return:

$$
R_{z}^{i}=\beta_{z}^{i} \cdot R_{m}+r_{z}^{i}
$$

We consider all risk buckets to have the same systematic component, and allow the prior

\footnotetext{
${ }^{17}$ In an alternative hypothesis, participants in LC do not have special insights and their investment in LC is not part of the active component but only a fraction of the market portfolio. In that case, the composition of risk buckets within LC is not given by the investor's risk aversion, as the optimal shares in the market portfolio are constant across investors. This hypothesis is strongly rejected by the data in the results section.
} 
about the market sensitivity of LC returns to be investor specific. That is, for all $z=1, \ldots, 35$ : $\beta_{z}^{i}=\beta_{L}^{i}$. This assumption is tested in Subsection 5.218

We can rewrite the investor's budget constraint in the following way:

$$
c^{i}=W^{i}\left[x_{f}^{i}+x_{Z+1}^{i} R_{m}+\sum_{z=1}^{Z} x_{z}^{i} r_{z}^{i}\right]
$$

where $x_{Z+1}^{i}$ is the total exposure to market risk, given both by the investor's direct holdings of market portfolio, $x_{m}^{i}$, and, indirectly, by her accumulation of market risk as a by-product of the position in the active portfolio:

$$
x_{Z+1}^{i}=x_{m}^{i}+\sum_{z=1}^{Z} x_{z}^{i} \beta_{z}^{i}
$$

Following Treynor and Black (1973), we use Sharpe's Diagonal Model for covariance among securities. It posits that the returns of the different investment opportunities are related to each other only through their relationships with a common underlying factor. In the case of LC, the loans in the program are assumed to be related to other securities only through the market's effect on LC systematic risk. That is, the independent returns, defined in equation (4), are uncorrelated.

\section{Assumption 1. Sharpe's Diagonal Mode 19}

$$
\text { for all } n \neq h: \operatorname{cov}\left[r_{n}^{i}, r_{h}^{i}\right]=0
$$

To grasp the intuition behind this assumption consider, for example, how an increase in macroeconomic risk (i.e., financial crisis) is captured in the model. Macro fluctuations, which can trigger correlated defaults across buckets, represent an underlying common factor. Such a common factor is reflected in the systematic component of equation (4) and can vary across investors and time.

\footnotetext{
${ }^{18}$ Note that under this assumption, the prior about the systematic risk $V_{z}$ introduced in Subsection 2.2 is investor specific and it is given by $V_{z}^{i}=\left(\beta_{L}^{i}\right)^{2} \cdot \operatorname{var}\left[R_{m}\right]$, for all $z=1, \ldots, 35$.

${ }^{19}$ Allowing a time dimension, the independent returns are also uncorrelated across time. That is, the portfolio choices within LC are time-independent.
} 
Under assumption 1, our theoretical framework transforms the original investor budget constraint in equation (3) into the portfolio in equation (5), composed of a risk-free asset and $Z+1$ mutually independent securities. The investor is constrained to non-negative positions in all the LC buckets: $x_{z} \geq 0$ for $z=1, \ldots, 35$. The following problem describes the portfolio choice of investor $i$ :

$$
\max _{x_{f},\{x\}_{z=1}^{Z+1}} E u\left(W^{i}\left[x_{f}+x_{Z+1} R_{m}+\sum_{z=1}^{Z} x_{z} r_{z}^{i}\right]\right)
$$

For all active buckets with $x_{z}>0$, the first order condition characterizing the optimal portfolio share is 20

$$
f \circ c\left(x_{z}^{i}\right): E\left[u^{\prime}\left(c^{i}\right) \cdot W^{i}\left(r_{z}^{i}-1\right)\right]=0
$$

A first-order linearization of the first order condition around expected consumption results in the following optimality condition:

$$
E\left[r_{z}^{i}\right]-1=\left(-\frac{u^{\prime \prime}\left(E\left[c^{i}\right]\right)}{u^{\prime}\left(E\left[c^{i}\right]\right)}\right) \cdot W^{i} x_{z}^{i} \cdot \operatorname{var}\left[r_{z}^{i}\right]
$$

Note that, even when LC projects are affected by market fluctuations, the optimal investment in bucket $z$ is independent of market risk considerations, or the volatility of the investor's securities outside LC. This is because the holding of market portfolio, $x_{Z+1}$ in equation (6), optimally adjusts to account for the indirect market risk imbedded in LC or any other security in the active portfolio of the investor. The optimal LC portfolio depends only on the investor's risk aversion, and the expectation and variance of the independent return of each bucket $z$.

Rewriting investor-specific idiosyncratic risk in terms of the common parameter $\sigma_{z}$, computed in equation (1), and substituting the expectation of the independent return, $E\left[r_{z}^{i}\right]$, with expected return $E\left[R_{z}\right]$, common across investors, computed in equation (2), we derive our main empirical equation. Let $A^{i}$ be the set of all active risk buckets -i.e. $A^{i}=\left\{z \leq 35 \mid x_{z}^{i}>0\right\}-$,

\footnotetext{
${ }^{20}$ The minimum investment per loan is $\$ 25$. This limit results in discrete intervals over which the number of projects financed, $n_{z}^{i}$, is unaltered by a marginal change in $x_{z}$. The following first order condition characterizes the optimal portfolio within these discrete intervals.
} 
then for all $z \in A^{i}$ :

$$
E\left[R_{z}\right]=\theta^{i}+A R A^{i} \cdot \frac{W^{i} x_{z}^{i}}{n_{z}^{i}} \sigma_{z}^{2}
$$

where:

$$
\begin{aligned}
\theta^{i} & \equiv 1+\beta_{L}^{i} E\left[R_{m}\right] \\
A R A^{i} & \equiv-\frac{u^{\prime \prime}\left(E\left[c^{i}\right]\right)}{u^{\prime}\left(E\left[c^{i}\right]\right)}
\end{aligned}
$$

The parameter $A R A^{i}$ corresponds to the Absolute Risk Aversion. It captures the extra expected return needed to leave the investor indifferent when taking extra risk. The parameter $\theta^{i}$ collects the systematic component of the LC investment, which is constant across buckets. We estimate this parameter as a person-specific constant (the constant is investment-specific when investors make multiple portfolio choices). Thus, our estimation procedure does not require the computation of the LC portfolio covariance with the market. Our main estimation procedure exploits only the active risk buckets $\left(z \in A^{i}\right)$; we show in Subsection 7.1 that the estimated risk preferences are consistent with those implied by the forgone buckets $\left(z \notin A^{i}\right)$.

We show in Appendix A that the same equation characterizes the optimal LC portfolio and allows recovering the curvature of the utility function under three alternative preference specifications: 1) when investors are averse to losses in their overall wealth, 2) an extreme version of narrow framing in which investors' preferences within LC are independent from their attitude towards risk in other settings, and 3) when investor utility depends in a non-separable way on both the overall wealth level and the income flow from specific components of the portfolio (for example, as in Barberis and Huang (2001), Barberis, Huang and Thaler (2006), and Cox and Sadiraj (2006)).

The expected lifetime wealth of the investors is unknown and we therefore cannot compute the Relative Risk Aversion (RRA) ${ }^{21}$ However, for the purpose of comparing our estimates with

\footnotetext{
${ }^{21}$ Although we cannot compute RRA, in Section 6 we infer its elasticity with respect to wealth, based on the
} 
results from laboratory experiments, we follow that literature and define a relative risk aversion based solely on the income generated by investing in LC (income-based RRA), which we denote $\rho$ (see, for example, Holt and Laury (2002)):

$$
\rho^{i} \equiv A R A^{i} \cdot I_{L}^{i} \cdot\left(E\left[R_{L}^{i}\right]-1\right)
$$

where $I_{L}^{i}$ is the total investment in LC, $I_{L}^{i}=W^{i} \sum_{z=1}^{35} x_{z}^{i}$, and $E\left[R_{L}^{i}\right]$ is the expected return on the LC portfolio, $E\left[R_{L}^{i}\right]=\sum_{z=1}^{35} x_{z}^{i} E\left[R_{z}\right]$.

\section{Data and Sample}

Our sample covers the period between October 2007 and April 2008. Below we provide summary statistics of the investors' characteristics and their portfolio choices, and a description of the sample construction.

\subsection{Investors}

For each investor we observe the home address zip code, verified by LC against the checking account information, and age, gender, marital status, home ownership status, and net worth, obtained through Acxiom, a third party specialized in recovering consumer demographics. Acxiom uses a proprietary algorithm to recover gender from the investor names, and matches investor names and home addresses to available public records to recover age, marital status, home ownership status, and an estimate of net worth. Such information is available at the beginning of the sample.

Table 1, panel B, shows the demographic characteristics of the LC investors. The average investor in our sample is 43 years old, 8 years younger than the average respondent in the Survey of Consumer Finances (SCF). As expected from younger investors, the proportion of married participants in LC $(56 \%)$ is lower than in the SCF $(68 \%)$. Men are over-represented elasticity of ARA: $\xi_{R R A, W}=\xi_{A R A, W}+1$. 
among participants in financial markets, they account for $83 \%$ of the LC investors; similarly, the faction of male respondents in the SCF is $79 \%$. In terms of income and net worth, investors in LC are comparable to other participants in financial markets, who are typically wealthier than the median U.S. households. The median net worth of $\mathrm{LC}$ investors is estimated between $\$ 250,000$ and $\$ 499,999$, significantly higher then the median U.S. household $(\$ 120,000$ according to the $\mathrm{SCF}$ ), but similar to the estimated wealth of other samples of financial investors. Korniotis and Kumar (2010), for example, estimate the wealth of clients in a major U.S. discount brokerage house in 1996 at $\$ 270,000$.

To obtain an indicator of housing wealth, we match investors' information with the Zillow Home Value Index by zip code. The Zillow Index for a given geographical area is the value of the median property in that location, estimated using a proprietary hedonic model based on house transactions and house characteristics data, and it is available at a monthly frequency. Figure 2 shows the geographical distribution of the 1,624 zip codes where the LC investors are located (Alaska, Hawaii, and Puerto Rico excluded). Although geographically disperse, LC investors tend to concentrate in urban areas and major cities. Table 1 shows the descriptive statistics of median house values on October 2007 and their variation during the sample period-October 2007 to April 2008.

\subsection{Sample Construction}

We consider as a single portfolio choice all the investments an individual makes within a calendar month 22 The full sample contains 2,168 investors, 5,191 portfolio choices, which results in 50,254 investment-bucket observations. To compute the expected return and idiosyncratic variance of the investment-bucket in equations (2) and (1), we use as the risk free interest rate, the 3-year yield on Treasury Bonds at the time of the investment. Table 2 , panel A, reports the descriptive statistics of the investment-buckets. The median expected return is $12.2 \%$, with an idiosyncratic

\footnotetext{
${ }^{22}$ This time window is arbitrary and modifying it does not change the risk aversion estimates. We chose a calendar month for convenience, since it coincides with the frequency of the real estate price data that we use to proxy for wealth shocks in the empirical analysis.
} 
variance of $3.6 \%$. Panel $\mathrm{B}$, describes the risk and return of the investors' LC portfolios. The median portfolio expected return in the sample is $12.2 \%$, almost identical to the expectation at the bucket level, but the idiosyncratic variance is substantially lower, $0.0054 \%$, due to risk diversification across buckets.

Our estimation method imposes two requirements for inclusion in the sample. First, estimating risk aversion implies recovering two investor specific parameters from equation (8). Therefore, a point estimate of the risk aversion parameter can only be recovered when a portfolio choice contains more than one risk bucket.

Second, our identification method relies on the assumption that all projects in a risk bucket have the same expected return and variance. Under this assumption investors will always prefer to exhaust the diversification opportunities within a bucket, i.e., will prefer to invest $\$ 25$ in two different loans belonging to bucket $z$ instead of investing $\$ 50$ in a single loan in the same bucket. It is possible that some investors choose to forego diversification opportunities if they believe that a particular loan has a higher return or lower variance than the average loan in the same bucket. Because investors' private insights are unobservable to the econometrician, such deviations from full diversification will bias the risk aversion estimates downwards. To avoid such bias we exclude all non-diversified components of an investment. Thus, the sample we base our analysis on includes: 1) investment components that are chosen through the optimization tool, which automatically exhausts diversification opportunities, and 2) diversified investment components that allocate no more than $\$ 50$ to any given loan.

After imposing these restrictions, the analysis sample has 2,168 investors and 3,745 portfolio choices. The descriptive statistics of the analysis sample are shown in Table 2, column 2 . As expected, the average portfolio in the analysis sample is smaller and distributed across a larger number of buckets than the average portfolio in the full sample. The average portfolio expected return is the same across the two samples, while the idiosyncratic variance in the analysis sample is smaller. This is expected since the analysis sample excludes non-diversified investment components. 
In the wealth analysis, we further restrict the sample to those investors that are located in zip codes where the Zillow Index is computed. This reduces the sample to 1,806 investors and 3,145 portfolio choices. This final selection does not alter the observed characteristics of the portfolios significantly (Table 2, column 3). To maintain a consistent analysis sample throughout the discussion that follows, we perform all estimations using this final subsample unless otherwise noted.

\section{$5 \quad$ Risk Aversion Estimates}

Our baseline estimation specification is based on equation (8). We allow for an additive error term, such that for each investor $i$ we estimate the following equation:

$$
E\left[R_{z}\right]=\theta^{i}+A R A^{i} \cdot \frac{W^{i} x_{z}^{i}}{n_{z}^{i}} \sigma_{z}^{2}+\varepsilon_{z}^{i}
$$

There is one independent equation for each active bucket $z$ in the investor's portfolio. The median portfolio choice in our sample allocates funding to 10 buckets, which provides us with multiple degrees of freedom for estimation. We estimate the parameters of equation (12) with Ordinary Least Squares.

Figure 3 shows four examples of portfolio choices. The vertical axis measures the expected return of a risk bucket, $E\left[R_{z}\right]$, and the horizontal axis measures the bucket variance weighted by the investment amount, $W^{i} x_{z}^{i} \sigma_{z}^{2} / n_{z}^{i}$. The slope of the linear fit is our estimate of the absolute risk aversion and it is reported on the top of each plot.

The error term captures deviations from the efficient portfolio due to the $\$ 25$ constraint for the minimum investment, measurement errors by investors, and real or perceived private information. The OLS estimates will be unbiased as long as the error component does not vary systematically with bucket risk. We discuss and provide evidence in support of this identification assumption below. 


\subsection{Results}

The descriptive statistics of the estimated parameters of equation (8) for each portfolio choice are presented in Table 3. The average estimated ARA across all portfolio choices is 0.0368. Investors exhibit substantial heterogeneity in risk aversion, and its distribution is left skewed: the median ARA is 0.0439 and the standard deviation 0.0246. This standard deviation overestimates the standard deviation of the true ARA parameter across investments because it includes the estimation error that results from having a limited number of buckets per portfolio choice. Following Arellano and Bonhomme (2009), we can recover the variance of the true ARA by subtracting the expected estimation variance across all portfolio choices. The calculated standard deviation of the true ARA is 0.0237 , indicating that the estimation variance is small relative to the variance of risk aversion across investments ${ }^{23}$ The range of the ARA estimates is consistent with the estimates recovered in the laboratory. Holt and Laury (2002), for example, obtain ARA estimates between 0.003 and 0.109 , depending on the size of the bet.

The experimental literature often reports the income-based RRA, defined in equation (11). To compare our results with those of laboratory participants, we report the distribution of the implied income-based RRA in Table 3. The mean income-based RRA is 2.85 and its distribution is right-skewed (median 1.62). This parameter scales the measure of absolute risk aversion according to the lottery expected income; therefore, it mechanically increases with the size of the bet. Table 3 reports the distribution of expected income from LC. The mean expected income is $\$ 130$, substantially higher than the bet in most laboratory experiments. Not surprisingly, although the computed ARA in experimental work is typically larger than our estimates, the income-based RRA parameter is smaller, ranging from 0.3 to 0.52 (see for example Chen and Plott (1998), Goeree, Holt and Palfrey (2002), Goeree, Holt and Palfrey (2003), and Goeree and Holt (2004)). Our results are comparable to Holt and Laury (2002), who also estimate risk

${ }^{23}$ The variance of the true ARA is calculated as:

$$
\operatorname{var}\left[A R A^{i}\right]=\operatorname{var}\left[\widehat{A R A}^{i}\right]-E\left[\widehat{\sigma}_{A R A^{i}}^{2}\right]
$$

where the first term is the variance of the OLS ARA point estimates across all investments, and the second term is the average of the variance of the OLS ARA estimates across all investments. 
aversion for agents facing large bets and (implicitly) find income-based RRA similar to ours, 1.2. Finally, Choi et al. (2007) report risk premia with a mean of 0.9, which corresponds to an income-based RRA of 1.8 in our setting. That paper also finds right skewness in their measure of risk premia.

Our findings imply that the high levels of risk aversion exhibited by experimental subjects extrapolate to actual small-stake investment choices. Rabin and Thaler (2001) and Rabin and Thaler (2002) emphasize that such levels of risk aversion with small stakes are difficult to reconcile, within the expected utility framework over total wealth, with the observable behavior of agents in environments with larger stakes. This suggests that EU framework on overall wealth cannot describe agents behavior in our environment. We show in the Appendix that the ARA estimated here describes the curvature of the utility function in other preference frameworks that are consistent with observed risk behavior over small and large stake gambles (Barberis and Huang (2001) and Cox and Sadiraj (2006)). In such alternate preference specifications, agents' ARA depends on, both, the level of initial wealth and the income generated by the gamble. This implies that the estimated level of ARA may change with the expected income of investments. Nevertheless, the elasticity of ARA with respect to investor's wealth, our focus in the next section, is consistent across different investment decisions and levels of expected income in these frameworks. We provide evidence in Section 7 that our conclusions regarding the relationship between investor risk aversion and wealth extrapolates to other decisions within LC.

The parameter $\theta$, defined in equation (9), captures the systematic component of LC. In our framework, the systematic component is driven by the common covariance between all LC bucket returns and the market, $\beta_{L}$. The average estimated $\theta$ is 1.086 , which indicates that the average investor requires a systematic risk premium of $8.6 \%$. The estimated $\theta$ presents very little variation in the cross section of investors (coefficient of variation $2.7 \%$ ), when compared to the variation in the ARA estimates (coefficient of variation of $67 \%$ ) ${ }^{24}$ Note that our ARA

\footnotetext{
${ }^{24}$ As with the ARA, the estimation variance is small relative to the variance across investments. The standard deviation of $\hat{\theta}$ is 0.0269 , while the standard deviation of $\theta$ after subtracting the estimation variance is 0.0260 .
} 
estimates are not based on this risk premium; instead, they are based on the marginal premium required to take an infinitesimally greater idiosyncratic risk.

Table 4 presents the average and standard deviation of the estimated parameters by month. The average ARA increases from 0.032 during the first three months, to 0.039 during the last three. This average time series variation is potentially due to heterogeneity across investors as well as within investor variation, since not all investors participate in LC every month. The analysis in the next section disentangles the two sources of variation.

The estimated $\theta \mathrm{s}$ imply that the average systematic risk premium increases from $6.3 \%$ to $9.2 \%$ between the first and last three months of the sample period. Note that the LC web page provides no information on the systematic risk of LC investments. Thus, this change is solely driven by changes in investors' beliefs about the potential correlation between the likelihood of default of LC loans and aggregate macroeconomic shocks (covariance between LC returns and market returns, $\left.\beta_{L}\right)$, or about the expected market risk premium $\left(E\left[R_{m}\right]\right)$. This pattern indicates that wealth shocks are potentially correlated with changes in investors' beliefs about risk and return on financial assets. Thus, we cannot infer the elasticity of RRA to wealth by observing changes in the share of risky assets after a wealth shock, as they may be simply reflecting changes in beliefs about the underlying distribution of risky returns. Our proposed empirical strategy in the next section overcomes this identification problem.

\subsection{Belief Heterogeneity and Bias: The Optimization Tool}

Above we interpret the observed heterogeneity of investor portfolio choices as arising from differences in risk preferences. Such heterogeneity may also arise if investors have different beliefs about the risk and returns of the LC risk buckets. Note that differences in beliefs about the systematic component of returns will not induce heterogeneity in our estimates of the ARA. This type of belief heterogeneity will be captured by variations in $\theta$ across investors. The evidence in the previous section suggests that investors have relatively common priors about this systematic component of the returns, i.e., common priors about LC's beta, $\beta_{L}$. 
However, the parameter $\theta$ will not capture heterogeneity of beliefs that affects the relative risk and expected return across buckets. This is the case if investors believe the market sensitivity of returns to be different across LC buckets, i.e. if $\beta_{z}^{i} \neq \beta_{L}^{i}$ for some $z=1, \ldots, 35$; or if investors' priors about the stochastic properties of the buckets idiosyncratic return differ from the ones computed in equations $(1)$ and $\left[2\right.$, i.e. $E^{i}\left[R_{z}\right] \neq E\left[R_{z}\right]$ or $\sigma_{z}^{i} \neq \sigma_{z}$ for some $z=1, \ldots, 35$. In such cases, the equation characterizing the investor's optimal portfolio is given by:

$$
E\left[R_{z}\right]=\theta^{i}+\left[A R A^{i} \cdot B_{\sigma}^{i}+B_{\mu}^{i}+B_{\beta}^{i}\right] \cdot \frac{W^{i} x_{z}^{i}}{n_{z}^{i}} \sigma_{z}^{2}
$$

This expression differs from our main specification equation 8 in three bias terms: $B_{\sigma} \equiv$ $\left(\sigma_{z}^{i} / \sigma_{z}\right)^{2}, B_{\mu} \equiv\left(E\left[R_{z}\right]-E^{i}\left[R_{z}\right]\right) /\left(W^{i} x_{z}^{i} \sigma_{z}^{2} / n_{z}^{i}\right)$, and $B_{\beta} \equiv\left(\beta_{z}^{i}-\beta_{L}^{i}\right) /\left(W^{i} x_{z}^{i} \sigma_{z}^{2} / n_{z}^{i}\right)$.

Two features of the LC environment allow us to estimate the magnitude of the overall bias from these sources. First, LC posts on its website an estimate of the idiosyncratic default probabilities for each bucket. Second, LC offers an optimization tool to help investors diversify their loan portfolio. The tool constructs the set of efficient loan portfolios, given the investor's total amount in LC - i.e., the minimum idiosyncratic variance for each level of expected return. Investors then select, among all the efficient portfolios, the preferred one according to their own risk preferences. Importantly, the tool uses the same modeling assumptions regarding investors' beliefs that we use in our framework: the idiosyncratic probabilities of default are the ones posted on the website and the systematic risk is common across buckets, i.e. $\beta_{z}=\beta_{L}{ }^{25}$

Thus, we can measure the estimation bias by comparing, for the same investment, the ARA estimates obtained independently from two different components of the portfolio choice: the loans suggested by the tool and those chosen manually. If investors' beliefs do not deviate systematically across buckets from the information posted on LC's website and from the assumptions of the optimization tool, we should find investor preferences to be consistent across the two measures. Note that our identification assumption does not require that investors agree with LC assumptions. It suffices that the difference in beliefs does not vary systematically across

\footnotetext{
${ }^{25}$ See Appendix $\mathrm{B}$ for the derivation of the efficient portfolios suggested by the optimization tool.
} 
buckets. For example, our estimates are unbiased if investors believe that the idiosyncratic risk is $20 \%$ higher than the one implied by the probabilities reported in LC, across all buckets. Note, moreover, that our test is based on investors' beliefs at the time of making the portfolio choices. These beliefs need not to be correct ex post.

For each investment, we independently compute the risk aversion implied by the component suggested by the optimization tool (Automatic buckets) and the risk aversion implied by the component chosen directly by the investor (Non-Automatic buckets). Figure 4 provides an example of this estimation. Both panels of the figure plot the expected return and weighted idiosyncratic variance for the same portfolio choice. Panel A includes only the Automatic buckets, suggested by the optimization tool. Panel B includes only the Non Automatic buckets, chosen directly by the investor. The estimated ARA using the Automatic and Non-Automatic bucket subsamples are 0.048 and 0.051 respectively for this example.

We perform the independent estimation above for all portfolio choices that have at least two Automatic and two Non-Automatic buckets. To verify that investments that contain an Automatic component are representative of the entire sample, we compare the extreme cases where the entire portfolio is suggested by the tool and those where the entire portfolio is chosen manually. The median $A R A$ is 0.0440 and 0.0441 respectively, and the mean difference across the two groups is not statistically significant at the standard levels. This suggests that our focus in this subsection on investments with an Automatic component is representative of the entire investment sample.

Table 5. panel A, reports the descriptive statistics of the ARA estimated using the Automatic and the Non-Automatic buckets. The average ARA is virtually identical across the two estimations (Table 5, columns 1 and 2), and the means are statistically indistinguishable at the $1 \%$ level. This implies that, if there is a bias our $A R A$ estimates induced by differences in beliefs, its mean across investments is zero. Column 3 shows the descriptive statistics of the investment-by-investment difference between the two ARA estimates. The mean is zero and the distribution of the difference is concentrated around zero, with kurtosis 11.72 (see Figure 5). 
This implies that the bias is close to zero not only in expectation, but investment-by-investment.

These results suggest that investors' beliefs about the stochastic properties of the loans in LC do not differ substantially from those posted on the website. They also suggest that investors' choices are consistent with the assumption that the systematic component is constant across buckets. Overall, these findings validate the interpretation that the observed heterogeneity across investor portfolio decisions is driven by differences in risk preferences.

In Table 5, panels $\mathrm{B}$ and $\mathrm{C}$, we show that the difference in the distribution of the estimated ARA from the automatic and non-automatic buckets is insignificant both during the first and second half of the sample period. This finding is key for interpreting the results in the next section, where we explore how the risk aversion estimates change in the time series with changes in housing prices. There, we interpret any observed time variation in the ARA estimates as a change in investor risk preferences over time.

Table 5, columns 4 through 6 , show that the estimated risk premia, $\theta$, also exhibit almost identical mean and standard deviations when obtained independently using the Automatic and Non-Automatic investment components. The mean difference is not statistically difference at the $1 \%$ confidence level. This suggests that our estimates of the risk premium are unbiased 26

It is worth reiterating that these findings do not imply that investors' beliefs about the overall risk of investing in LC do not change during the sample period. On the contrary, the observed average increase in the estimated systematic risk premium in Table 4 is also observed in panels $\mathrm{B}$ and $\mathrm{C}$ of Table 5 . $\theta$ increases by 2.5 percentage points between the first and second halves of the sample. The results in Table 5 imply that changes in investors' beliefs are fully accounted for by a common systematic component across all risk buckets and, thus, do not bias our risk aversion estimates.

\footnotetext{
${ }^{26}$ In Appendix $B$ we show that a bias in the risk premia estimate may arise because the optimization tool's suggestion is potentially suboptimal relative to the one implied by condition (8). The intuition is that, for any given return, condition (8) minimizes the variance of the investor's entire risky portfolio, while the optimization tool minimizes the variance of the LC portion of her portfolio only. The results imply that the inclusion of the Automatic component of investments does not bias our estimations and further validates the conclusions of this section.
} 


\section{Risk Aversion and Wealth}

This section explores the relationship between investors' risk taking behavior and wealth. We estimate the elasticity of ARA with respect to wealth, and use it to obtain the elasticity of RRA with respect to wealth, based on the following expression:

$$
\xi_{R R A, W}=\xi_{A R A, W}+1
$$

where $\xi_{R R A, W}$ and $\xi_{A R A, W}$ refer to the wealth elasticities of RRA and ARA, respectively. For robustness, we also estimate the elasticity of the income-based RRA in equation (11), $\xi_{\rho, W}$.

We exploit the panel dimension of our data and estimate these elasticities, both, in the cross section of investors and, for a given investor, in the time series. In the cross section, wealthier investors exhibit lower ARA and higher RRA when choosing their portfolio of loans within LC; we refer to these elasticity estimates with the superscript $x s$ to emphasize that they do not represent the shape of individual preferences (i.e., $\xi_{A R A, W}^{x s}, \xi_{R R A, W}^{x s}, \xi_{\rho, W}^{x s}$ ). And, in the time series, investor specific RRA increases after experiencing a negative wealth shock; that is, the preference function exhibits decreasing RRA. The contrasting signs of the cross sectional and investor-specific wealth elasticities indicate that preferences and wealth are not independently distributed across investors.

\subsection{Wealth and Wealth Shock Proxies}

Below, we describe our proxies for wealth in the cross section of investors, and for wealth shocks in the time series. Since the bulk of the analysis uses housing wealth as a proxy for investor wealth, we focus the discussion in this section on the subsample of investors that are homeowners 27

\footnotetext{
${ }^{27}$ None of the results in this section is statistically significant in the subsample of investors that are renters. This is expected since housing wealth and total wealth are less likely to be correlated for renters, particularly in the time series. However, this is also possibly due to lack of power, since only a small fraction of the investors in our sample are renters.
} 


\subsubsection{Cross Section}

We use Acxiom's imputed net worth as of October 2007 as a proxy for wealth in the cross section of investors. As discussed in Section 4. Acxiom's imputed net worth is based on a proprietary algorithm that combines names, home address, credit rating, and other data from public sources. To account for potential measurement error in this proxy, we use a separate indicator for investor wealth in an errors-in-variable estimation: median house price in the investor's zip code at the time of investment. Admittedly, house value is an imperfect indicator wealth; it does not account for heterogeneity in mortgage level or the proportion of wealth invested in housing. Nevertheless, as long as the measurement errors are uncorrelated across the two proxies, a plausible assumption in our setting, the errors-in-variable estimation provides an unbiased estimate of the cross-sectional elasticity of risk aversion to wealth.

The errors-in-variables approach works in our setting because risk preferences are obtained independently from wealth. If, for example, risk aversion were estimated from the share of risky and riskless assets in the investor portfolio, this estimate would inherit the errors in the wealth measure. As a result, any observed correlation between risk aversion and wealth could be spuriously driven by measurement errors. This is not a concern in our exercise.

\subsubsection{Wealth Shocks}

House values dropped sharply during our sample period. Since housing represents a substantial fraction of household wealth in the U.S., this decline implied an important negative wealth shock for home-owners. ${ }^{28}$ We use this source of variation, to estimate the wealth elasticity of investorspecific risk aversion in the subsample of home-owners that invest in LC. In this subsample the average zip code house price declines $4 \%$ between October 2007 and April 2008 29

The drop in house value is an incomplete measure of the change in the investor overall wealth.

\footnotetext{
${ }^{28}$ According to the Survey of Consumer Finances of 2007, the value of the primary residence accounts for approximately $32 \%$ of total assets for the median U.S. family (see Bucks, Kennickel, Mach and Moore (2009)).

${ }^{29}$ In addition, the time series house price variation is heterogeneous across investors: the median house price decline is $3.6 \%$.
} 
It is important, then, to analyze the potential estimation bias introduced by this measurement error. Any time-invariant measurement error or unobserved heterogeneity across investors is captured by the investor fixed effect and does not affect our elasticity estimates. However, the estimate of the wealth elasticity of risk aversion will be biased if the percentage change in wealth is different from the drop in house values. If the drop in house prices is disproportionately large relative to the change in overall wealth, our estimates of the elasticity will be biased towards zero. And, alternatively, if the percentage decline in house values underestimates the change in the investor's total wealth, then the wealth elasticity of risk aversion will be overestimated (in absolute value). Finally, if the measurement error in the computation of the wealth shock is not systematic, we will estimate the elasticity with the classic attenuation bias, in which case our estimates provide a lower bound for the elasticities of risk aversion to wealth. In subsection 6.3 , we analyze how our conclusions are affected under different types of measurement error.

\subsection{Cross-Sectional Evidence}

We begin by exploring non-parametrically the relationship between the risk aversion estimates

and our two wealth proxies for the cross section of home-owner investors in our sample. Figure 6 plots a kernel-weighted local polynomial smoothing of the risk aversion measure. The horizontal axis measures the $(\log )$ net worth and the $(\log )$ median house price in the investor's zip code at the time of the portfolio choice. ARA is decreasing in both wealth proxies, while income-based RRA is increasing.

Turning to parametric evidence, we estimate the cross sectional elasticity of ARA to wealth using the following regression:

$$
\ln \left(A R A_{i}\right)=\beta_{0}+\beta_{1} \ln \left(N e t W \text { orth }_{i}\right)+\omega_{i}
$$

The left hand side variable is investor $i$ 's average $(\log )$ ARA, obtained by averaging the ARA estimates recovered from the investor's portfolio choices during our sample period. The right-hand side variable is investor $i$ 's imputed net worth. Thus, the estimated $\beta_{1}$ corresponds 
to the cross-sectional wealth elasticity of ARA, $\xi_{A R A, W}^{x s}$.

To account for measurement error in our wealth proxy we estimate specification (14) in an errors-in-variables model by instrumenting imputed net worth with the average (log) house value in the zip code of residence of investor $i$ during the sample period. Since the instrument varies only at the zip code level, in the estimation we allow the standard errors in specification (14) to be clustered by zip code.

Table 6 shows the estimated cross sectional elasticities with OLS and the errors-in-variables model (panels A and B respectively). Our preferred estimates from the errors-in-variables model indicate that the elasticity of ARA to wealth in the cross section is -0.059 and statistically significant at the $1 \%$ confidence level (Table 6, column 1). The non-parametric relationship is confirmed: wealthier investors exhibit a lower ARA. The OLS elasticity estimate is biased towards zero. This attenuation bias is consistent with classical measurement error in the wealth proxy.

The estimated ARA elasticity and equation (13) imply that the wealth-based RRA elasticity to wealth is positive, $\widehat{\xi}_{R R A, W}^{x s}=0.94$. Column 2 shows the result of estimating specification (14) using the income-based RRA as the dependent variable. The income-based RRA increases with investor wealth in the cross section, and the point estimate, 0.12 , is also significant at the $1 \%$ level. The sign of the estimated elasticity coincide with that implied by the ARA elasticity. Overall, the results consistently indicate that the RRA is larger for wealthier investors in the cross section.

\subsection{Within-Investor Estimates}

The above elasticity, obtained from the variation of risk aversion and wealth in the cross section, can be taken to represent the form of the utility function of the representative investor only under strong assumptions. Namely, when the distributions of wealth and preferences in the population are independent 30 To identify the functional form of individual risk preferences we estimate the

\footnotetext{
${ }^{30}$ Chiappori and Paiella (2008) formally prove that any within-investor elasticity of risk aversion to wealth can be supported in the cross section by appropriately picking such joint distribution.
} 
ARA elasticity using within-investor time series variation in wealth:

$$
\ln \left(A R A_{i t}\right)=\alpha_{i}+\beta_{2} \ln \left(\text { HouseValue }_{i t}\right)+\omega_{i t} .
$$

The left-hand side variable is the estimated ARA for investor $i$ in month $t$. The right-hand side variable of interest is the (log) median house value of the investor's zip code during the month the risk aversion estimate was obtained (i.e., the month the investment in LC takes places). The right-hand side of specification (15) includes a full set of investor dummies as controls. These investor fixed effects (FE) account for all cross sectional differences in risk aversion levels. Thus, the elasticity $\beta_{2}$ recovers the sensitivity of ARA to investor-specific shocks to wealth.

By construction, the parameter $\beta_{2}$ can be estimated only for the subsample of investors that choose an LC portfolio more than once in our sample period. Although the average number of portfolio choices per investor is 1.8 , the median investor chooses only once during our analysis period. This implies that the data over which we obtain the within investor estimates using (15) comes from less than half of the original sample. To insure that the results below are representative for the full investor sample, we also show the results of estimating specification (15) without the investor FE to corroborate that the conclusions of the previous section are unchanged when estimated on the subsample of investors that chose portfolios more than once.

Table 7 reports the parameter estimates of specification $(15)$, before and after including the investor FE (Panels A and B respectively). The FE results represent our estimated wealth elasticities of ARA, $\xi_{A R A, W}$. The sign of the estimated within-investor elasticity of ARA to wealth (column 1) is the same as in the cross section: absolute risk aversion is decreasing in investor wealth.

Equation (13) and the estimated wealth elasticity of ARA imply a negative wealth-based RRA to wealth changes for a given investor, $\xi_{R R A, W}$, of -1.82 . Column 2 reports the result of estimating specification (15) using the income-based RRA as the dependent variable. The point estimate, -4.18 , also implies a negative relationship between this alternative measure of RRA and wealth. These results consistently suggest that investors' utility function exhibits decreasing 
relative risk aversion.

Measurement error in our proxy for wealth is unlikely to change this conclusion. Classical measurement error would imply that the point estimate is biased towards zero; this estimate is therefore a lower bound (in absolute value) for the actual wealth elasticity of risk aversion. The (absolute value) of the elasticity could be overestimated if the percentage decline in house values underestimates the change in the investor's total wealth. However, for error in measurement to account for the sign of the elasticity, the overall change in wealth has to be three times larger than the percentage drop in house value ${ }^{31}$ This is unlikely in our setting since stock prices dropped $10 \%$ and investments in bonds had a positive yield during our sample period ${ }^{32}$ Therefore, even if measurement error biases the numerical estimate, it is unlikely to affect our conclusions regarding the shape of the utility function.

The observed positive relationship between investor RRA and wealth in the cross section from the previous section changes sign once one accounts for investor preference heterogeneity. The comparison of the estimates with and without investor FE of panels A and B in Table 7 confirms it. This implies that investors preferences and wealth are not independently distributed in the cross section. Investors with different wealth levels may have different preferences, for example, because more risk averse individuals made investment choices that made them wealthier. Alternatively, an unobserved investor characteristic, such as having more educated parents, may cause an investor the be wealthier and to be more risk averse. The results indicate that characterizing empirically the shape of the utility function requires, first, accounting for such heterogeneity.

\footnotetext{
${ }^{31}$ We estimate the elasticity of ARA with respect to changes in house value to be -2.82 . Let $W$ be overall wealth and $H$ be house value, then: $\xi_{A R A, W}=\frac{d \ln A R A}{d \ln W}=-2.82 \cdot \frac{d \ln H}{d \ln W}$. The wealth elasticity of RRA is positive only if $\xi_{A R A, W}>-1$, which requires $\frac{d \ln W}{d \ln H}>2.82$.

${ }^{32}$ Between October 1, 2007 and April 30, 2008 the S\&P 500 Index dropped 10\% and the performance of U.S. investment grade bond market was positive - Barclays Capital U.S. Aggregate Index increased approximately $2 \%$.
} 


\section{Consistency of Preferences}

In this section we show that the estimated level and wealth elasticity of risk aversion consistently extrapolate to other investors' decisions. For that, we exploit the different dimensions of the investment decision in LC: the total amount to invest in LC, the loans to include in the portfolio, and the portfolio allocation across these loans.

\subsection{Foregone Risk Buckets}

The investor-specific ARA is estimated in Section 5 based on the allocation of funds across the risk buckets included in her portfolio. Yet, investors select in their portfolio only a subset of the buckets available. We show in this subsection that including the foregone buckets in the median investor's portfolio would lower her expected utility given her estimated ARA. Thus, investors' estimated level of risk aversion is consistent with the preferences revealed by their selection of loans.

The median investor in the analysis sample assigns funds to 10 out of 35 risk buckets (see Table 2, panel B). Our empirical specification (12) characterizes the allocation of the median investment among the 10 active buckets without using the corresponding equations describing the choice of the foregone 25 buckets. We use these conditions to develop a consistency test for investors' choices.

For each investor $i$, let $A^{i}$ be the set of active risk buckets. The optimal portfolio model described in Section 3 , predicts that, for all foregone risk buckets $z \notin A^{i}$, the first order condition (8), evaluated at the minimum investment amount per project of $\$ 25$, is negative - i.e. the nonnegative constraint is binding. The resulting linearized condition for all $z \notin A^{i}$ is:

$$
\text { foc }_{\text {foregone }}=E\left[R_{z}\right]-\theta^{i}-A R A^{i} \cdot 25 \cdot \sigma_{z}^{2}<0
$$

We test this prediction by calculating foc $_{\text {foregone }}$ for every foregone bucket using the parameters $\left\{\theta=\hat{\theta}^{i}, A R A^{i}=\widehat{A R A}^{i}\right\}$ estimated with specification $\sqrt{12}$. To illustrate the procedure, suppose 
that investor $i$ chooses to allocate funds to 10 risk buckets. From that choice we estimate a constant $\hat{\theta}^{i}$ and an absolute risk aversion $\widehat{A R A}^{i}$ using specification $\sqrt{12}$. For each of the 25

foregone risk buckets we calculate foc $_{\text {foregone }}$ above. Then we repeat the procedure for each investment in our sample and test whether foc foregone is negative.

Using the procedure above we calculate 85,366 values for $f o c_{\text {foregone. The average value }}$ for the first order condition evaluated at the foregone buckets is -0.000529 , with a standard deviation of 0.0000839 . This implies that the $95 \%$ confidence interval for foc $_{\text {foregone }}$ is $[-0.00069,-0.00036]$. The null hypothesis that the mean is equal to zero is rejected with a $t=-6.30$. If we repeat this test investment-by-investment, the null hypothesis that mean of $f o c_{\text {foregone }}$ is zero is rejected for the median investment with a $t=-1.99$.

These results confirm that the risk preferences recovered from the investors' portfolio choices are consistent with the risk preferences implied by the foregone investment opportunities in LC.

\subsection{Amount Invested in LC}

In this subsection we test whether the cross-sectional and within-investor elasticities of risk aversion to wealth consistently extrapolate to the investor's decision of how much to invest in LC. Our model in Section 3 delivers testable implications for the relationship between an investor's risk preferences and her overall holdings of the efficient LC portfolio. Namely, when relative risk aversion decreases (increases) in wealth, then the share of wealth invested in LC will increase (decrease) in wealth (see Appendix C). We can use these predictions, both, to provide an independent validation for the results on the elasticity of risk aversion to wealth based on the risk aversion estimates obtained in Section 5 , and to explore the connection between investors' risk preferences across different types of choices.

We test the above implications by estimating specifications (14) and (15) using the $(\log )$ amount invested in LC as dependent variable. Table 6 and 7 (column 3) report the estimated cross sectional and within investor elasticities.

We find that the investment amount is increasing with investor wealth in the cross section 
(Table 6, column 3). The elasticity is smaller than one, which suggests that the ratio of the investment to wealth is decreasing. These estimates are consistent with decreasing ARA and increasing RRA cross sectional elasticities reported in Tables 6. That is, agents that exhibit larger risk aversion in their portfolio choice within LC are also characterized by lower risk tolerance when choosing how much to invest in the program.

The estimated wealth elasticity of total investment in LC is positive and grater than one when we add investor fixed effects (Table 6 column 3). This implies that, for a given investor, the ratio of investment to wealth is increasing. These results mirror those in the previous subsection concerning the estimates of the elasticity of investor specific ARA with respect to changes in wealth. We can therefore conclude that changes in wealth have same qualitative effect on the investors' attitudes towards risk, both, when deciding her portfolio within LC and when choosing how much to allocate in LC relative to other opportunities.

Providing evidence of this link is impossible in a laboratory environment where the investment amount is exogenously fixed by the experiment design. Our results suggest that preference parameters obtained from marginal choices can plausibly explain decision making behavior in broader contexts.

\section{Conclusion}

In this paper we estimate risk preference parameters and their elasticity to wealth based on the actual financial decisions of a panel of U.S. investors participating in a person-to-person lending platform. The average absolute risk aversion in our sample is 0.0368. We also measure the relative risk aversion based on the income generated by investing in LC (income-based RRA). We find a large degree of heterogeneity, with an average income-based RRA of 2.85 and a median of 1.62. These findings are similar to those obtained in laboratory studies; they provide an external validation in a real life investment environment to the estimates obtained from 
laboratory experiments 33

We exploit the panel dimension of our data and estimate the elasticity of ARA and RRA with respect to wealth, both, in the cross section of investors and, for a given investor, in the time series. In the cross section, wealthier investors exhibit lower ARA and higher RRA when choosing their portfolio of loans within LC. In the time series, investor specific RRA increases after experiencing a negative wealth shock; that is, the preference function exhibits decreasing RRA. The contrasting signs of the cross sectional and investor-specific wealth elasticities indicate that investors' preferences and wealth are not independently distributed in the cross section. Therefore, to empirically characterize the shape of the utility function, one needs to take the properties of the joint distribution of preferences and wealth into account.

Parallel to experimental results, in settings where agents maximize expected utility over total wealth, the observed levels of risk aversion inside LC are difficult to reconcile with reasonable choices in large stake environments ${ }^{34}$ Our findings are consistent with a behavioral model in which utility depends (in a non-separable way) on both the overall wealth level and the flow of income from specific components of agent's portfolio. This is in line with Barberis and Huang (2001) and Barberis et al. (2006), which propose a framework where agents exhibit loss aversion over changes in specific components of their overall portfolio, together with decreasing relative risk aversion over their entire wealth. In the expected utility framework, Cox and Sadiraj (2006) propose a utility function with two arguments (income and wealth) where risk aversion is defined over income, but it is sensitive to the overall wealth level. Since our estimates of risk aversion refer to the local curvature of preferences over changes in income, they characterize risk preferences over income irrespectively of the form of the utility function over total wealth. Indeed, we show in the Appendix that our estimates of risk aversion characterize the local curvature of preferences over changes in income for different preference frameworks - i.e., expected utility, loss aversion,

\footnotetext{
${ }^{33}$ For estimation of risk aversion in real life environments, see also Jullien and Salanie (2000), Jullien and Salanie (2008), Bombardini and Trebbi (2007), Cohen and Einav (2007), Harrison, Lau and Towe (2007a), Chiappori, Gandhi, Salanie and Salanie (2008), Post, van den Assem, Baltussen and Thaler (2008), Chiappori, Gandhi, Salanie and Salanie (2009), and Barseghyan, Prince and Teitelbaum (2010).

${ }^{34}$ This is commonly referred to as the Rabin's Critique (Rabin (2000) and Rabin and Thaler (2001)). See also Rubinstein (2001) for an alternative interpretation of this phenomenon within the expected utility theory.
} 
and narrow framing-.

\section{References}

Arellano, Manuel, and Stephane Bonhomme (2009) 'Identifying Distributional Characteristics in Random Coefficients Panel Data Models.' Working Paper

Barberis, Nicholas, and Ming Huang (2001) 'Mental Accounting, Loss Aversion, and Individual Stock Returns.' The Journal of Finance 56(4), 1247-1292

Barberis, Nicholas, Ming Huang, and Richard H. Thaler (2006) 'Individual preferences, monetary gambles, and stock market participation: A case for narrow framing.' The American Economic Review 96(4), 1069-1090

Barseghyan, Levon, Jeffrey Prince, and Joshua Teitelbaum (2010) 'Are Risk Preferences Stable Across Contexts? Evidence from Insurance Data.' The American Economic Review

Barsky, Robert B., F. Thomas Juster, Miles S. Kimball, and Matthew D. Shapiro (1997) 'Preference Parameters and Behavioral Heterogeneity: An Experimental Approach in the Health and Retirement Study.' The Quarterly Journal of Economics 112(2), 537-579

Blake, David (1996) 'Efficiency, Risk Aversion and Portfolio Insurance: An Analysis of Financial Asset Portfolio Held by Inverstors in the United Kingdom.' The Economic Journal 106(136), 1175-1192

Blume, Marshall, and Irwin Friend (1975) 'The Demand for Risky Assets.' The American Economic Review 65(5), 900-922

Bombardini, Matilde, and Francesco Trebbi (2007) 'Risk Aversion and Expected Utility Theory: an Experiment with Large and Small Stakes.' Working Paper

Brunnermeier, Markus, and Stefan Nagel (2008) 'Do Wealth Fluctuations Generate TimeVarying Risk Aversion? Micro-evidence on Individuals.' The American Economic Review 98(3), 713-36

Bucks, Brian, Arthur Kennickel, Traci Mach, and Kevin Moore (2009) 'Changes in U.S. Family Finances from 2004 to 2007: Evidence from the Survey of Consumer Finances.' Federal Reserve Bulletin 95, A1-A55

Calvet, Laurent, and Paolo Sodini (2009) 'Twin Picks: Disentangling the Determinants of RiskTaking in Household Portfolios.' Working Paper

Calvet, Laurent E., John Y. Campbell, and Paolo Sodini (2009) 'Fight or Flight? Portfolio Rebalancing by Individual Investors.' The Quarterly Journal of Economics 124(1), 301-348

Campbell, John, and John Cochrane (1999) 'By Force of Habit: A Consumption Based Explanation of Aggregate Stock Market Behavior.' Journal of Political Economy 107, 205-251 
Chen, Kay Yut, and Charles Plott (1998) 'Non-linear Behavior in Sealed Bid First Price Auctions.' Games and Economic Behavior 25(1), 34-78

Chiappori, Pierre-Andre, Amit Gandhi, Bernard Salanie, and Francois Salanie (2008) 'You Are What You Bet: Eliciting Risk Attitudes from Horse Races.' Working Paper

_ (2009) 'Identifying Preferences under Risk from Discrete Choices.' American Economic Review 99(2), 356 - 362

Chiappori, Pierre-Andre, and Monica Paiella (2008) 'Risk Aversion is Constant: Evidence from Panel Data.' Working Paper

Choi, Syngjoo, Raymond Fisman, Douglas Gale, and Shachar Kariv (2007) 'Consistency and Heterogeneity of Individual Behavior under Uncertainty.' The American Economic Review 97(5), 1921-1938

Cicchetti, Charles, and Jeffrey Dubin (1994) 'A Microeconomic Analysis of Risk Aversion and the Decision to Self-Insure.' Journal of Political Economy 102(11), 169-186

Cohen, Alma, and Liran Einav (2007) 'Estimating Risk Preferences from Deductible Choice.' The American Economic Review 97(3), 745-788

Cohn, Richard A., Wilbur G. Lewellen, Ronald C. Lease, and Gary G. Schlarbaum (1975) 'Individual Investor Risk Aversion and Investment Portfolio Composition.' The Journal of Finance 30(2), 605-620

Cox, James, and Vjollca Sadiraj (2006) 'Small- and Large-stakes Risk Aversion: Implications of Concavity Calibration for Decision Theory.' Games and Economic Behavior 56, 45-60

Goeree, Jacob, and Charles Holt (2004) 'A Model of Noisy Introspection.' Games and Economic Behavior 46(2), 365-382

Goeree, Jacob, Charles Holt, and Thomas Palfrey (2002) 'Quantal Response Equilibrium and Overbidding in Private-Value Auctions.' Journal of Economic Theory 104(1), 247-272

(2003) 'Risk Averse Behavior in Generalized Matching Pennies Games.' Games and Economic Behavior 45(1), 97-113

Gollier, Christian (2001) 'Wealth Inequality and Asset Pricing.' Review of Econmic Studies $68(1), 181-203$

Gomes, Francisco, and Alexander Michaelides (2008) 'Asset Pricing with Limited Risk Sharing and Heterogeneous Agents.' The Review of Financial Studies 21(1), 415-448

Guiso, Luigi, and Monica Paiella (2008) 'Risk Aversion, Wealth, and Background Risk.' Working Paper

Guvenen, Fatih (2009) 'A Parsimonious Macroeconomic Model for Asset Pricing.' Econometrica $77(6), 1711-1750$ 
Harrison, Glenn, Morten Lau, and Charles Towe (2007a) 'Naturally Occurring Preferences and Exogenous Laboratory Experiments: A Case Study of Risk Aversion.' Econometrica $75(2), 433-458$

Harrison, Glenn, Morten Lau, and Elisabet Rutstrom (2007b) 'Estimating Risk Attitudes in Denmark: A Field Experiment.' Scandinavian Journal of Economics 109(2), 341-368

Holt, Charles A., and Susan K. Laury (2002) 'Risk Aversion and Incentive Effects.' The American Economic Review 92(5), 1644-1655

Jullien, Bruno, and Bernard Salanie (2000) 'Estimating Preferences Under Risk: The Case of Racetrack Bettors.' The Journal of Political Economy 108(3), 503-530

_ (2008) 'Empirical Evidence on the Preferences of Racetrack Bettors.' In Efficiency of Sports and Lottery Markets, ed. Don Hausch and Bill Ziemba pp. 27-49

Kocherlakota, Narayana (1996) 'The Equity Premium: It's Still a Puzzle.' Journal of Economic Literature 34(1), 42-71

Korniotis, George, and Alok Kumar (2010) 'Do Older Investors Make Better Investment Decisions?' Review of Economics and Statistics. Forthcoming

Morin, Roger-A., and A. Fernandez Suarez (1983) 'Risk Aversion Revisited.' The Journal of Finance 38(4), 1201-1216

Post, Thierry, Martijn J. van den Assem, Guido Baltussen, and Richard H. Thaler (2008) 'Deal or No Deal? Decision Making under Risk in a Large-Payoff Game Show.' American Economic Review 98(1), 38-71

Rabin, Matthew (2000) 'Risk Aversion and Expected-Utility Theory: A Calibration Theorem.' Econometrica 68(5), 1281-1292

Rabin, Matthew, and Richard Thaler (2001) 'Anomalies: Risk Aversion.' The Journal of Economic Perspectives 15(1), 219-232

_ (2002) 'Response from Matthew Rabin and Richard H. Thaler.' The Journal of Economic Perspectives 16(2), 229-230

Rubinstein, Ariel (2001) 'Comments on the Risk and Time Preferences in Economics'

Tanaka, Tomomi, Colin F. Camerer, and Quang Nguyen (2010) 'Risk and Time Preferences: Linking Experimental and Household Survey Data from Vietnam.' American Economic Review 100(1), 557-571

Treynor, Jack, and Fischer Black (1973) 'How to Use Security Analysis to Improve Portfolio Selection.' Journal of Business 46(1), 66-86 


\section{Appendix}

\section{A Alternative Utility Frameworks}

\section{A.1 Loss Aversion over Changes in Overall Wealth}

Consider the following preferences, which exhibit loss aversion with coefficient $\alpha$ around a benchmark consumption $\bar{c}$

$$
U=\alpha \cdot E[u(c) \mid c<\bar{c}] \cdot \operatorname{Pr}[c<\bar{c}]+E[u(c) \mid c>\bar{c}] \cdot \operatorname{Pr}[c>\bar{c}]]
$$

Since LC is a negligible part of the investor's wealth and the return is bounded between default and full repayment of all loans in the portfolio (see Table 2), the distribution of consumption is virtually unaffected by the realization of the independent component of bucket $\mathrm{z}$. Then, we define $\omega \equiv c-W x_{z} r_{z}$, which is independent from $r_{z}$, and approximate the distribution of $c$ with the distribution of $\omega: F(c) \approx F(\omega)$. Under this approximation, a marginal increase in $x_{z}$ does not affect the distribution $F(\omega)$ and the first order condition that characterizes the investor's portfolio choice is:

$$
f o c\left(x_{z}\right): \alpha \cdot E\left[u^{\prime}(c)\left(r_{z}-1\right) \mid \omega<\bar{c}\right] \cdot \operatorname{Pr}[\omega<\bar{c}]+E\left[u^{\prime}(c)\left(r_{z}-1\right) \mid \omega>\bar{c}\right] \cdot \operatorname{Pr}[\omega>\bar{c}]=0
$$

Since $\omega$ and $r_{z}$ are independently distributed, a first order linearization of expected marginal utility is given by:

$$
\begin{aligned}
E\left[u^{\prime}(c) r_{z} \mid \omega<\bar{c}\right] & =u^{\prime}(E[c \mid \omega<\bar{c}]) E\left[r_{z}\right]+u^{\prime \prime}(E[c \mid \omega<\bar{c}]) E\left[\left(\omega-E[\omega]+r_{z}-E\left[r_{z}\right]\right) r_{z} \mid \omega<\bar{c}\right] \\
& =u^{\prime}(E[c \mid \omega<\bar{c}]) E\left[r_{z}\right]+u^{\prime \prime}(E[c \mid \omega<\bar{c}]) \operatorname{var}\left[r_{z}\right]
\end{aligned}
$$

Replacing, the first order condition is approximated by:

$$
E\left[R_{z}\right]=\theta+\widetilde{A R A} \cdot W x_{z} \cdot \operatorname{var}\left[r_{z}\right]
$$

This condition is equivalent to the one in the body of the paper, irrespectively of the value of $\bar{c}$ or the existence of multiple kinks. However, the absolute risk aversion estimated using this equation is not the one evaluated around expected consumption, as in the body of the paper. Instead, it is a weighted average of the absolute risk aversions evaluated in the intervals defined by the loss aversion kinks:

$$
\begin{aligned}
& \widetilde{A R A} \equiv \lambda \cdot A R A^{-}+(1-\lambda) \cdot A R A^{+} \\
& \text {where : } \quad \lambda \equiv \frac{\alpha F[\bar{c}]}{\alpha F[\bar{c}]+(1-F[\bar{c}])} \\
& A R A^{-} \equiv-\frac{u^{\prime \prime}(E[c \mid c<\bar{c}])}{u^{\prime}(E[c \mid c<\bar{c}])} \\
& A R A^{+} \equiv-\frac{u^{\prime \prime}(E[c \mid c>\bar{c}])}{u^{\prime}(E[c \mid c>\bar{c}])}
\end{aligned}
$$


Still, as in the body of the paper, the optimal investment in a risk bucket $z$ is not explained by first order risk aversion; it is given by its expected return and second order risk aversion over the volatility of its idiosyncratic component.

\section{A.2 Narrow Framing}

Consider the following preferences:

$$
U=\sum_{k=1}^{K} E\left[u_{k}\left(I_{k} R_{k}\right)\right]
$$

$k=1, \ldots, K$ corresponds to the different sub-portfolios over which the investor exhibits local preferences. $y_{k}=I_{k} R_{k}$ is the income generated by the portfolio component $k$, given by $I_{k}$ and $R_{k}$, the total amount allocated in the sub-portfolio and the corresponding return.

Consider LC to be one of these sub-portfolios, so for $k=L$, the investor chooses the shares $\left\{x_{z}\right\}_{z=1}^{35}$ to be invested in each risk bucket so to maximize her utility over LC, for a given amount invested in the program, $I_{L}: E\left[u_{L}\left(I_{L} \cdot \sum_{z=1}^{35} x_{z} R_{z}\right)\right]$

The first order condition that characterizes all active buckets is:

$$
f \circ c\left(x_{z}\right): E\left[u_{L}^{\prime}\left(I_{L} \cdot \sum_{z=1}^{35} x_{z} R_{z}\right) R_{z}\right]-\mu_{L}=0
$$

where $\mu_{L}$ is the multiplier on the budget constraint $\sum_{z=1}^{35} x_{z}=1$.

A linearization around expected return results in the following expression:

$$
u_{L}^{\prime}\left(E\left[y_{L}\right]\right) E\left[R_{z}\right]+u_{L}^{\prime \prime}\left(E\left[y_{L}\right]\right) I_{L} \sum_{z=1}^{35} x_{z} E\left[\left(R_{z}-E\left[R_{z}\right]\right) \cdot R_{z}\right]=\mu_{L}
$$

From equation (4) and assuming $\beta_{z}=\beta_{L}$, the returns in LC are decomposed into a common systematic factor $\beta_{L} R_{m}$ and an idiosyncratic component $r_{z}$. Moreover, under the Diagonal Sharpe's Ratio in Assumptions 1, returns from different buckets co-move only through their market component. That is:

$$
\text { for all } z \neq z^{\prime}: \begin{aligned}
: & E\left[\left(R_{z^{\prime}}-E\left[R_{z^{\prime}}\right]\right) R_{z}\right]=\beta_{L}^{2} \cdot \operatorname{var}\left[R_{m}\right] \\
& E\left[\left(R_{z}-E\left[R_{z}\right]\right) R_{z}\right]=\beta_{L}^{2} \cdot \operatorname{var}\left[R_{m}\right]+\operatorname{var}\left[r_{z}\right]
\end{aligned}
$$

Replacing, the optimal portfolio within LC is characterized by the following expression:

$$
u_{L}^{\prime}\left(E\left[y_{L}\right]\right) \cdot E\left[R_{z}\right]+u_{L}^{\prime \prime}\left(E\left[y_{L}\right]\right) \cdot I_{L}\left(\beta_{L}^{2} \cdot \operatorname{var}\left[R_{m}\right]+x_{z} \cdot \operatorname{var}\left[r_{z}\right]\right)=\mu_{L}
$$

Rearranging terms, this leads to the same empirical equation as in the body of the paper:

$$
E\left[R_{z}\right]=\theta+A R A_{L} \cdot I_{L} x_{z} \cdot \operatorname{var}\left[r_{z}\right]
$$


$I_{L} x_{z}$ is the total amount invested in bucket $z$, equivalent to $W x_{z}$ in the body of the paper. Note that the systematic component is common to all risk buckets and therefore does not alter the portfolio composition within LC. It is recovered by the investor specific constant, which is given in this framework by:

$$
\theta \equiv \frac{\mu_{L}}{u^{\prime}\left(E\left[y_{L}\right]\right)}+A R A_{L} \cdot I_{L} \cdot \beta_{L}^{2} \cdot \operatorname{var}\left[R_{m}\right]
$$

If investors behave according to these preferences the ARA obtained from this empirical equation only characterizes the preferences within LC, $u_{L}$, for a given amount invested in the program, $I_{L}$ :

$$
A R A_{L} \equiv-\frac{u_{L}^{\prime \prime}\left(E\left[y_{L}\right]\right)}{u_{L}^{\prime}\left(E\left[y_{L}\right]\right)}
$$

We show in the paper this extreme version of narrow framing does not represent the preferences of the investors in LC. We show that the shape of the utility that follows from investors' choices within LC extrapolates to other decisions. In particular, the amount invested in LC: $I_{L}$. Moreover, follows from the expression above, that if investors exhibit narrow framing as presented here, realizations of returns in other sub-portfolios $k \neq L$ do not affect risk preferences $A R A_{L}$. We show that this is not the case; changes in the value of the investors' house affect the preferences exhibited within LC. However, more general forms of narrow framing are consistent with investors' choices, as explained in the following subsection.

\section{A.3 Preferences over Income and Wealth}

Consider, for example, investor preferences over, both, wealth and income of specific components of her portfolio:

$$
U=u\left(\left\{y_{k}\right\}_{k=1}^{K}, W\right)
$$

where, as before, $k=1, \ldots, K$ corresponds to the different sub-portfolios over which the investor exhibits local preferences, with income given by the amount invested in $k$ and the respective return, $y_{k}=I_{k} R_{k}$. The LC sub-portfolio is denoted $k=L$, with income defined as in the previous subsection: $y_{L}=I_{L} \sum_{z=1}^{35} x_{z} R_{z}$. W is the investor's overall wealth.

The first order condition that characterizes the active bucket $z$ within LC is similar to the one in the subsection above:

$$
f o c\left(x_{z}\right): E\left[u_{L}\left(\left\{y_{k}\right\}_{k=1}^{K}, W\right) R_{z}\right]-\mu_{L}=0
$$

where $u_{L}$ corresponds to the partial derivative of the utility function with respect to the income generated by the sub-portfolio $L$, and $\mu_{L}$ is the multiplier over the constraint $\sum_{z=1}^{35} x_{z}=1$. The linearization of this expression around the vector of expected income $\left\{E\left[y_{k}\right]\right\}_{k=1}^{K}$ is equivalent to expression (A.1):

$$
E\left[R_{z}\right]=\theta+A R A_{L} \cdot I_{L} x_{z} \cdot \operatorname{var}\left[r_{z}\right]
$$

Under Assumption (1), the investor specific parameter $\theta$ is defined as follows:

$$
\theta \equiv \frac{\mu_{L}}{u_{L}\left(\left\{E\left[y_{k}\right]\right\}_{k=1}^{K}, W\right)}-\sum_{k=1}^{K} \frac{u_{k L}\left(\left\{E\left[y_{k}\right]\right\}_{k=1}^{K}, W\right)}{u_{L}\left(\left\{E\left[y_{k}\right]\right\}_{k=1}^{K}, W\right)} \cdot I_{k} \cdot \beta_{k} \beta_{L} \cdot \operatorname{var}\left[R_{m}\right]
$$


where $u_{k L}$ is the cross derivative of the utility function with respect to the incomes generated by components $k$ and $L$. The absolute risk aversion recovers the investor's preferences over fluctuations in income; it is defined as follows:

$$
A R A_{L} \equiv-\frac{u_{L L}\left(\left\{E\left[y_{k}\right]\right\}_{k=1}^{K}, W\right)}{u_{L}\left(\left\{E\left[y_{k}\right]\right\}_{k=1}^{K}, W\right)} .
$$

This behavioral model, in which utility depends (in a non-separable way) on, both, the overall wealth level and the flow of income from specific components of the agent's portfolio, is in line with Barberis and Huang (2001) and Barberis et al. (2006), which propose a framework where agents exhibit loss aversion over changes in specic components of their overall portfolio, together with decreasing relative risk aversion over their entire wealth, consistent with the findings of this paper. In the expected utility framework, Cox and Sadiraj (2006) propose a utility function with two arguments (income and wealth) where risk aversion is defined over changes in income but it

is sensitive to the overall wealth level. Their suggested functional form implies $\frac{\partial A R A_{k}}{\partial y_{k}}<0$, which can reconcile low levels of ARA over high stake gambles and high ARA found in experimental literature when expected income from the lottery is small. Moreover, their functional form implies $\frac{\partial A R A_{k}}{\partial W}<0$, consistent with the findings in this paper.

\section{B Optimization Tool}

Those investors who follow the recommendation of the optimization tool make a sequential portfolio decision. First, they decide how much to invest in the entire LC portfolio. And second, they choose the desired level idiosyncratic risk in the LC investment, from which the optimization tool suggests a portfolio of loans.

The first decision, how much to invest in LC, follows the optimal portfolio choice model in Section 3 , where the security $z=L$ refer to the LC overall portfolio. The optimal investment in LC is therefore given by equation (7):

$$
E\left[r_{L}\right]-1=A R A^{i} \cdot W^{i} x_{L}^{i} \cdot \operatorname{var}\left[r_{L}\right]
$$

$\left(E\left[r_{L}\right]-1\right) / \operatorname{var}\left[r_{L}\right]$ corresponds to the investor's preferred risk-return ratio of the her LC portfolio. Although this ratio is not directly observable, we can infer it from the Automatic portfolio suggested by the optimization tool.

The optimization tool suggests the minimum variance portfolio given the investor's choice of idiosyncratic risk exposure. The investor marks her preferences by selecting a point in the $[0,1]$ interval: 0 implies fully diversified idiosyncratic risk (typically only loans from the A1 risk bucket) and 1 is the (normalized) maximum idiosyncratic risk. Figure 1 provides two snapshots of the screen that the lenders see when they make their choice.

For each point on the $[0,1]$ interval, the website generates the efficient portfolio of risk buckets. The loan composition at the interior of each risk bucket exhausts the diversification opportunities, with the constraint that an investment in a given loan cannot be less than $\$ 25$. 
The proposed share in each risk bucket $s_{z} \geq 0$ for $z=1, \ldots, 35$ satisfies the following program:

$$
\min _{\left\{s_{z}\right\}_{z=1}^{35}} \sum_{z=1}^{35} s_{z}^{2} \operatorname{var}\left[r_{z}\right]-\lambda_{0}\left\{\sum_{z=1}^{35} s_{z} E\left[R_{z}\right]-E\left[R_{L}\right]\right\}-\lambda_{1}\left\{\sum_{z=1}^{35} s_{z}-1\right\}
$$

$\operatorname{var}\left[r_{z}\right]$ and $E\left[R_{z}\right]$ are the idiosyncratic variance and expected return of the (optimally diversified) risk bucket $z$, computed in equations (1) and (2); and $E\left[R_{L}\right]$ is the demanded expected return of the entire portfolio.

Although the optimization tool operates under the assumption that LC has no systemic component, i.e., $\beta_{L}=0$, the suggested portfolio also minimizes variance for a given overall expected independent return, $E\left[r_{L}\right]$. That is, the problem is not affected by subtracting a common systematic component, $\beta_{L} E\left[R_{m}\right]$ on both sides of the expectation constraint. The resulting efficient portfolio suggested by the website satisfies the following condition for every active bucket $z$, for which $s_{z}>0$ :

$$
s_{z}=\lambda_{0}^{i} \frac{E\left[r_{z}\right]-\lambda_{1}^{i}}{\operatorname{var}\left[r_{z}\right]}
$$

That is, the share of LC investment allocated in bucket $z$ is proportional to the bucket's mean variance ratio. And the proportionality factor, $\lambda_{0}^{i}$, represents the risk preferences of the investor, imbedded in her chosen point on the $[0,1]$ interval:

$$
\lambda_{0}^{i}=\frac{\operatorname{var}\left[r_{L}\right]}{E\left[r_{L}\right]-\lambda_{1}^{i}}
$$

It is possible to recover, from the Automatic portfolio composition, the investor's preferred risk-return ratio. Combining equations $\mathrm{A.3}$ and $\mathrm{A.4}$ with the optimal LC investment condition A.2, we obtain the following expression:

$$
E\left[R_{z}\right]=\left(\beta_{L} E\left[R_{m}\right]+\lambda_{1}^{i}\right)+A R A^{i} \cdot W^{i} x_{L}^{i} s_{z}^{i} \cdot \operatorname{var}\left[r_{z}\right] \frac{\left(E\left[r_{L}\right]-\lambda_{1}^{i}\right)}{\left(E\left[r_{L}\right]-1\right)}
$$

Note that $W^{i} x_{L}^{i} s_{z}^{i}$ is the total amount invested in bucket $z$, which is equivalent to $W^{i} x_{z}^{i}$ in Section 3 .

Our estimates from the specification (12) may be biased by the inclusion of the Automatic choices. The magnitude of the bias is:

$$
\operatorname{bias}^{i}=\frac{E\left[R_{L}\right]-\theta_{A}^{i}}{E\left[R_{L}\right]-\theta_{N}^{i}}-1 .
$$

where $\theta_{N}^{i}$ and $\theta_{A}^{i}$ correspond to the investor specific constant in the specification equations (8) and A.5 respectively:

$$
\begin{aligned}
& \theta_{A}^{i} \equiv \lambda_{1}^{i}+\beta_{L} E\left[R_{m}\right] \\
& \theta_{N}^{i} \equiv 1+\beta_{L} E\left[R_{m}\right]
\end{aligned}
$$

We find that the intercepts estimated from Automatic and Non-Automatic choices $\left(\theta_{A}\right.$ and $\left.\theta_{N}\right)$ 
are equal (see Table 5). We therefore conclude that including Automatic choices does not bias our results.

\section{Investment Amount}

Limiting, for simplicity, the investor's outside options to the risk free asset and the market portfolio, the problem of investor $i$ is:

$$
\max _{x} E u\left(W^{i}\left(x_{f}^{i}+x_{m}^{i} R_{m}+x_{L}^{i} R_{L}\right)\right)
$$

where $R_{L}$ is the overall return of the efficient LC portfolio. The efficient LC portfolio composition is constructed renormalizing the optimal shares in equation (8): $R_{L}=\sum_{z=1}^{Z_{L}} \widetilde{x}_{z} R_{z}$ where $\widetilde{x}_{z} \equiv$ $x_{z} / \sum_{z=1}^{35} x_{z}$. A projection of the return $R_{L}$ against the market, parallel to equation (4), gives the investor's market sensitivity, $\beta_{L}^{i}$, and independent return:

$$
R_{L}=\beta_{L}^{i} \cdot R_{m}+r_{L}
$$

The investor's budget constraint can be rewritten as $c^{i}=W^{i}\left(x_{f}^{i}+\widetilde{x}_{m}^{i} R_{m}+x_{L}^{i} r_{L}\right)$, where $\widetilde{x}_{m}^{i}=x_{m}^{i}+x_{L}^{i} \beta_{L}^{i}$ incorporates the market risk imbedded in the LC portfolio.

A linearization of the first order condition around expected consumption results in the following optimality condition:

$$
E\left[R_{L}\right]=\theta^{i}+A R A^{i} \cdot I_{L}^{i} \cdot \operatorname{var}\left[r_{L}\right]
$$

where $I_{L}^{i}$ is the total investment in LC, $I_{L}^{i}=x_{L}^{i} W^{i}$. The composition of the LC portfolio is optimal; then, differentiating the expression above with respect to outside wealth and applying the envelope condition, we derive the following result:

$$
\begin{aligned}
& d \ln (A R A)=-d \ln \left(I_{L}\right) \\
& d \ln (R R A)=-d \ln \left(\frac{I_{L}}{W}\right)
\end{aligned}
$$

$A R A$ and $R R A$ refer to absolute and wealth-based relative risk aversion: $A R A \equiv-\frac{u^{\prime \prime}\left(E\left[c^{i}\right]\right)}{u^{\prime}\left(E\left[c^{i}\right]\right)}$ and $R R A \equiv-\frac{u^{\prime \prime}\left(E\left[c^{i}\right]\right)}{u^{\prime}\left(E\left[c^{i}\right]\right)} W$. We obtain the following testable implications:

Result 1. If the absolute risk aversion, ARA, decreases (increases) in outside wealth, then the amount invested in $L C, I_{L}$, increases (decreases) in outside wealth.

Result 2. If the wealth-based RRA decreases (increases) in outside wealth, then the share of wealth invested in $L C, I_{L} / W$, increases (decreases) in outside wealth.

We test these implications by estimating specifications (14) and (15) using the (log) amount invested in LC. 


\section{Figure 1: Portfolio Tool Screen Examples for a \$100 Investment}

A. Screen 1: Interest rate - Normalized Variance "Slider"

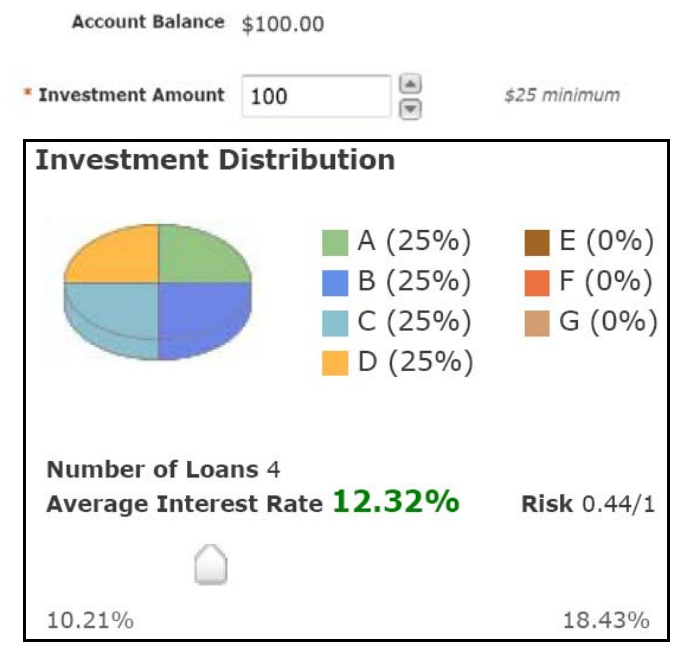

B. Screen 2: Suggested Portfolio Summary

\section{My Order Summary}

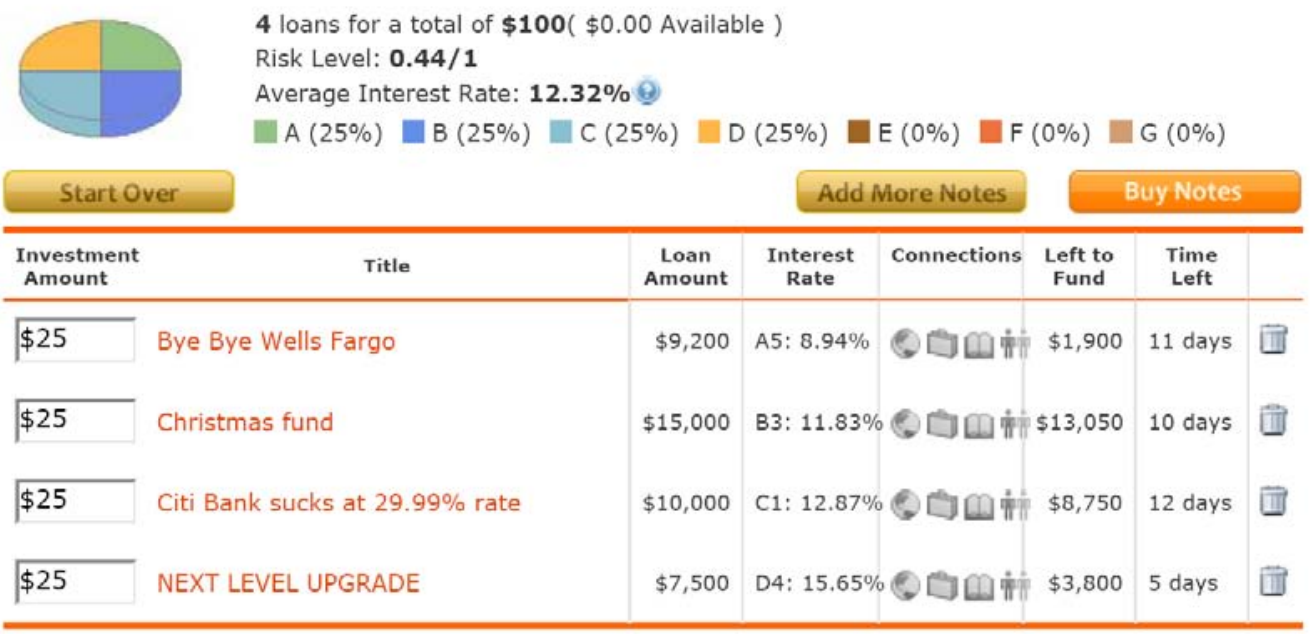

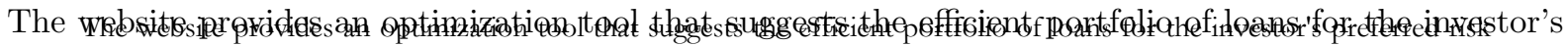

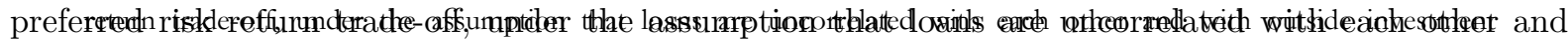

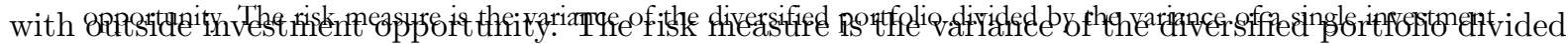

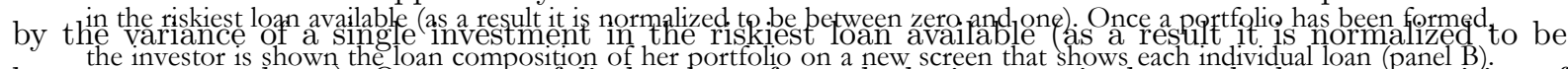

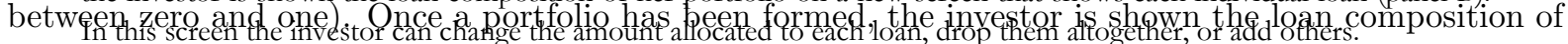
her portfolio on a new screen that shows each individual loan (panel B). In this screen the investor can change the amount allocated to each loan, drop them altogether, or add others.

Figure 1: Portfolio Tool Screen 3 Exxamples for a $\$ 100$ Investment 


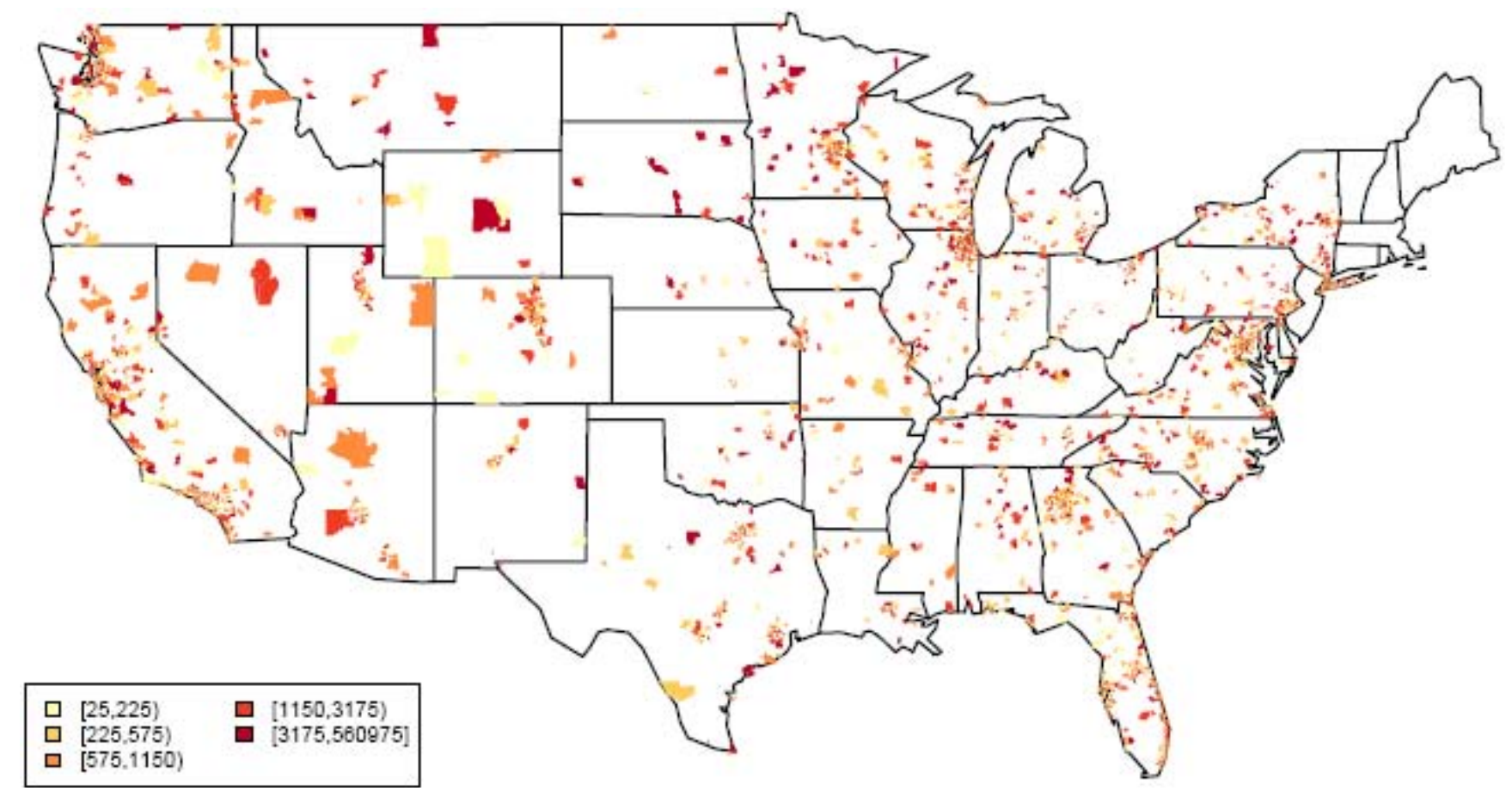

In color: zip codes with Lending Club investors. The color intensity reflects the total dollar amount invested in LC by investors in each zip code.

Figure 2: Geographical Distribution of Lending Club Investors 


\section{Figure 3: Examples of Risk Return Choices and Estimated RRA}

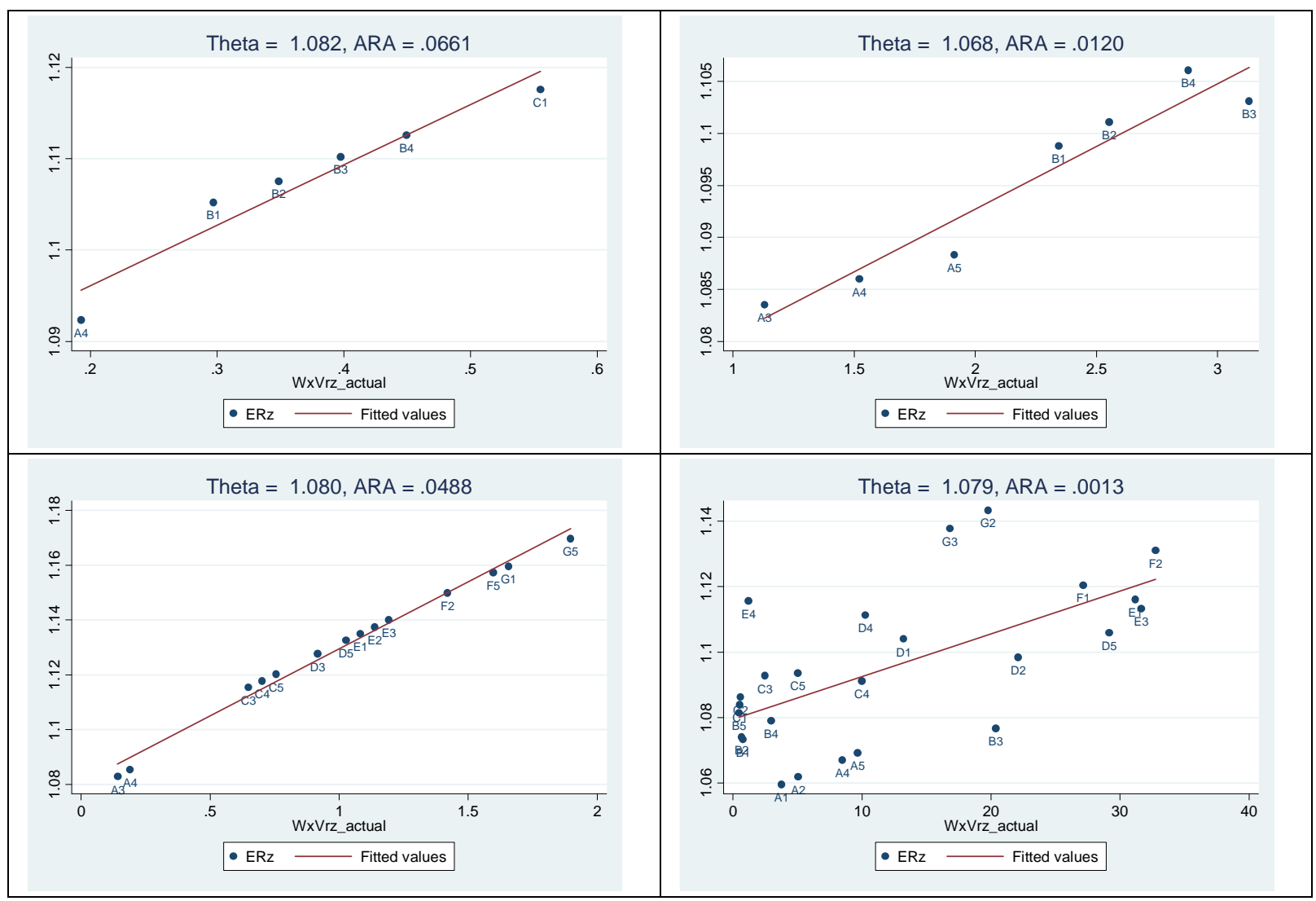

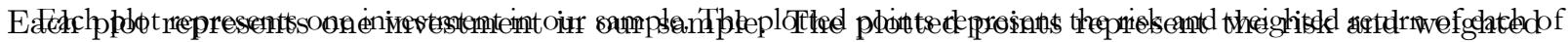

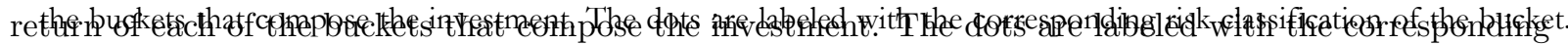

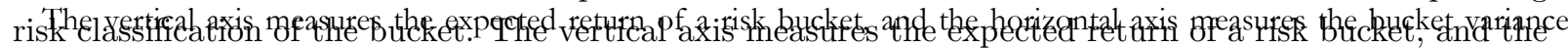
horeighted by the total investment in that bucket. The slope of the linear fit is our estimate af the absqlute aick aversion of (ARA linear int is our estimate of the absolute risk aversion (ARA). The intersection of this linear fit with the vertical axis is our estimate for the risk premium $(\theta)$.

Figure 3: Examples of Risk Return Choices and Estimated RRA 
Figure 4: Example of Risk Aversion Estimation Using Automatic and Non-Automatic

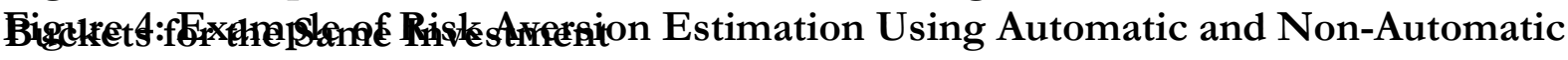
Buckets for the Same Investment

A. Automatic Buckets

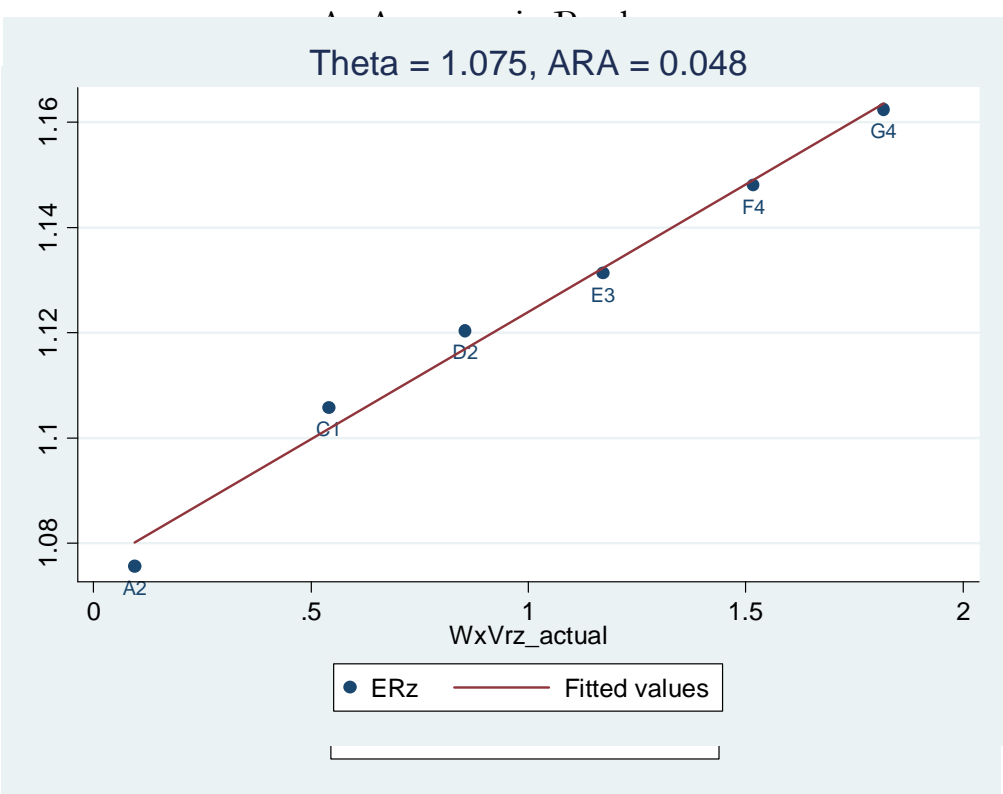

B. Non-Automatic Buckets

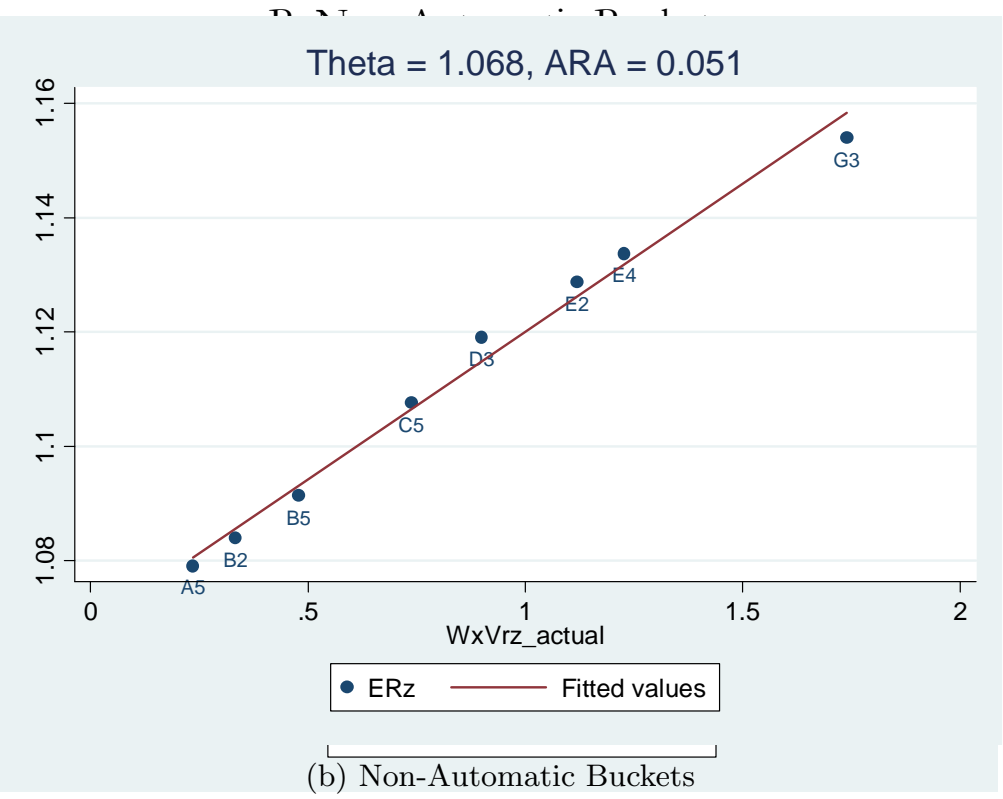

Both plots represent allocations to risk buckets of the same actual investment. As in Figyre 3 id the plotted points

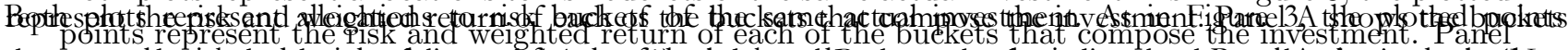

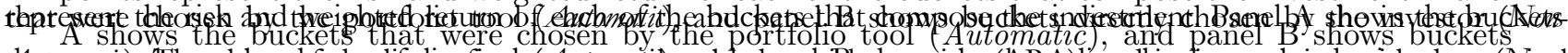

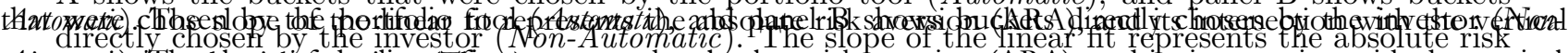

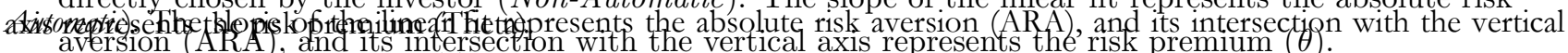
axis represents the risk premium (Theta).

Figure 4: Risk Aversion Estimation Example Using Automatic and Non-Automatic Buckets 
Figure 5: Distribution of the Difference in $A R A$ and $\theta_{0}$ Estimates Obtained

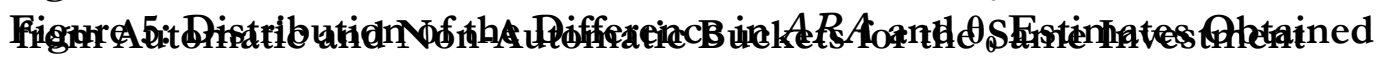
from Automatic and Non-Automatic Buckets for the Same Investment
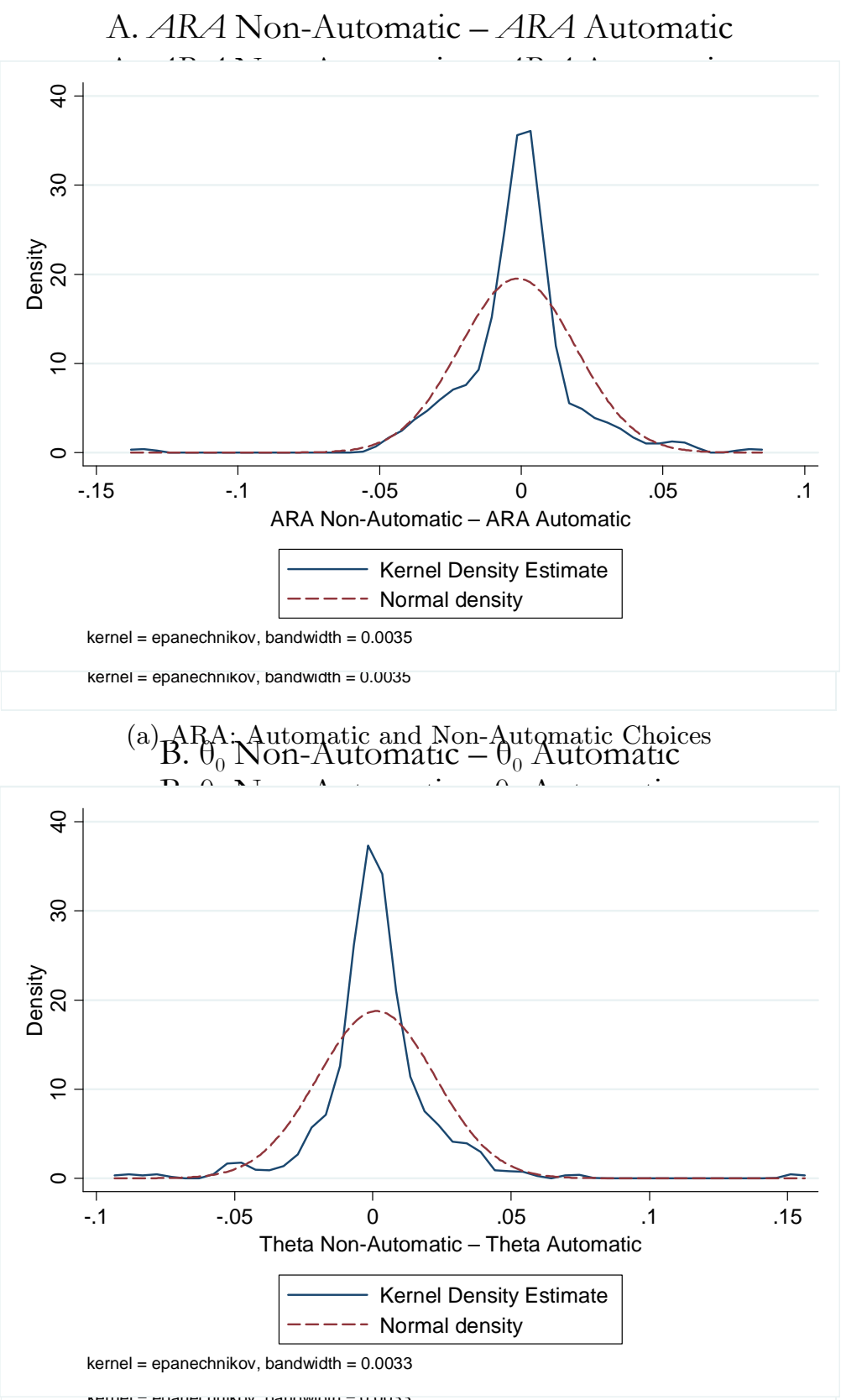

(b) $\theta$ : Automatic and Non-Automatic Choices

Difference between the estimate for ARA and $\theta_{0}$ obtained using buckets chosen directly by investors (Automatic) and

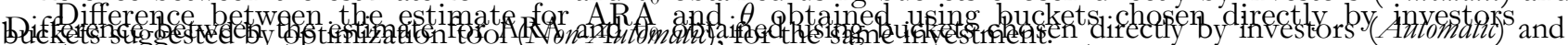

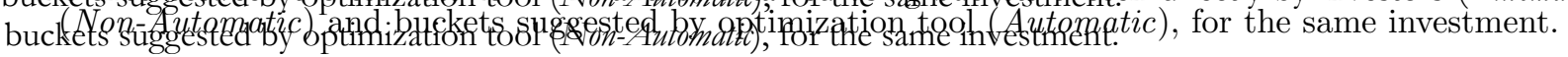

Figure 5: Investment-by-Investment Bias Distribution 


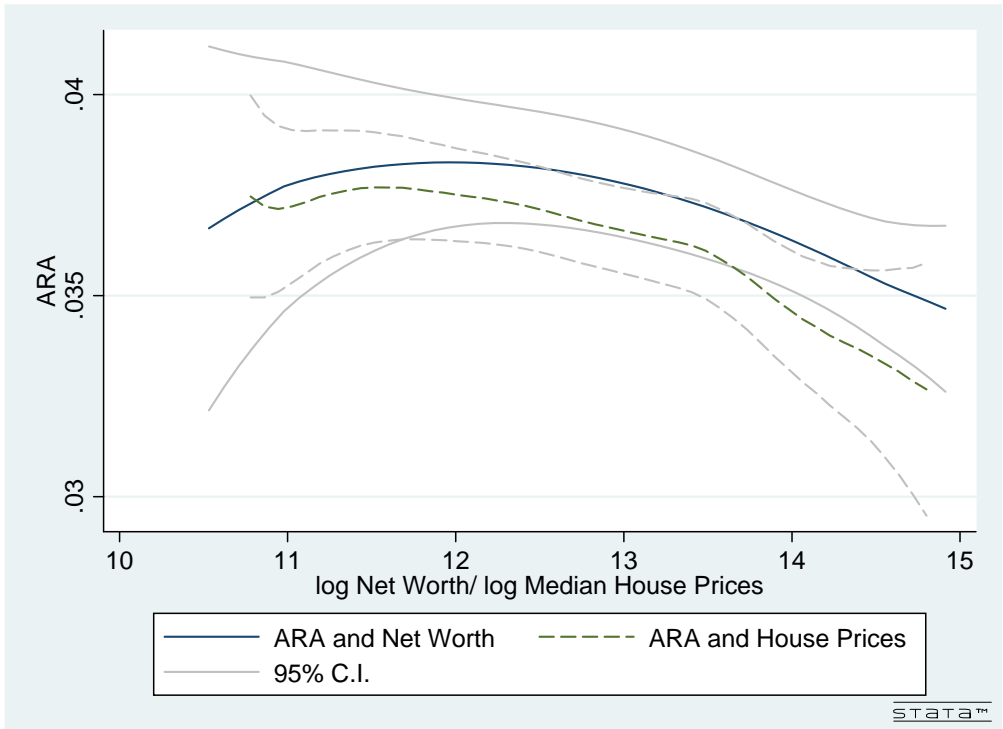

(a) ARA and Wealth

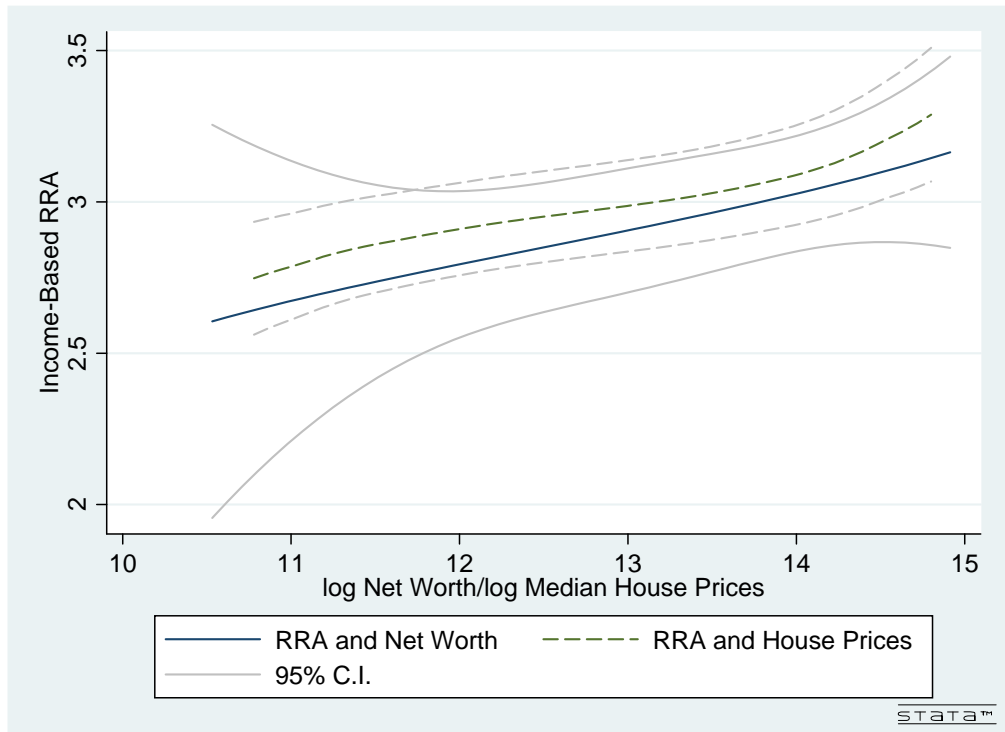

(b) Income-Based RRA and Wealth

Subsample: home-owners. The vertical axis plots a weighted local second degree polynomial smoothing of the risk aversion measure. The observations are weighted using an Epanechnikov kernel with a bandwidth of 0.75 . The horizontal axis measures the $(\log )$ net worth and the $(\log )$ median house price at the investor's zip code at the time of the portfolio choice, our two proxies for investor wealth.

Figure 6: Risk Aversion and Wealth in the Cross Section 


\begin{tabular}{|c|c|c|c|}
\hline Variable & Mean & Std. Dev. & Median \\
\hline \multicolumn{4}{|c|}{ A. Borrower Characteristics } \\
\hline FICO score & 694.3 & 38.2 & 688.0 \\
\hline Debt to Income & 0.128 & 0.076 & 0.128 \\
\hline Monthly Income $(\$)$ & $5,427.6$ & $5,963.1$ & $4,250.0$ \\
\hline Amount borrowed $(\$)$ & $9,223.7$ & $6,038.0$ & $8,000.0$ \\
\hline \multicolumn{4}{|c|}{ B. Investor Characteristics } \\
\hline Male & $83 \%$ & & $100 \%$ \\
\hline Age & 43.4 & 15.0 & 40.0 \\
\hline Married & $56 \%$ & & $100 \%$ \\
\hline Home Owner & $75 \%$ & & $100 \%$ \\
\hline Net Worth, Imputed $(\$ 1,000)$ & 663.0 & 994.4 & 375.0 \\
\hline Median House Value in Zip Code $(\$ 1,000)$ & 397.6 & 288.0 & 309.6 \\
\hline \% Change in House Price, $10-2007$ to $04-2008$ & $-4.0 \%$ & $5.8 \%$ & $-3.6 \%$ \\
\hline
\end{tabular}

Sources: Lending Club, Acxiom, and Zillow. October 2007 to April 2008. FICO scores and debt to income ratios are recovered from each borrower's credit report. Monthly incomes are self reported during the loan application process. Amount borrowed is the final amount obtained through Lending Club. Lending Club obtains investor demographics and net worth data through a third party marketing firm (Acxiom). Acxiom uses a proprietary algorithm to recover gender from the investor's name, and matches investor names, home addresses, and credit history details to available public records to recover age, marital status, home ownership status, and net worth. We use investor zip codes to match the LC data with real estate price data from the Zillow Home Value Index. The Zillow Index for a given geographical area is the median property value in that area.

\section{Table 1: Borrower and Investor Characteristics}




\begin{tabular}{|c|c|c|c|c|c|c|c|c|c|}
\hline \multirow[t]{2}{*}{ Sample/Subsample: } & \multicolumn{3}{|c|}{$\begin{array}{l}\text { All Investments } \\
\text { (1) }\end{array}$} & \multicolumn{3}{|c|}{$\begin{array}{c}\text { Diversified investments } \\
(2)\end{array}$} & \multicolumn{3}{|c|}{$\begin{array}{c}\text { With real estate data } \\
(3)\end{array}$} \\
\hline & Mean & S.D & Median & Mean & S.D & Median & Mean & S.D & Median \\
\hline \multicolumn{4}{|c|}{$\begin{array}{l}\text { A. Unit of observation: investor-bucket-month } \\
\qquad(\mathrm{N}=50,254)\end{array}$} & \multicolumn{3}{|c|}{$(\mathrm{N}=43,662)$} & \multicolumn{3}{|c|}{$(\mathrm{N}=37,248)$} \\
\hline Investment $(\$)$ & 302.8 & $2,251.4$ & 50.0 & 86.0 & 206.9 & 50.0 & 90.1 & 220.5 & 50.0 \\
\hline N Projects in Bucket & 1.9 & 1.8 & 1.0 & 2.0 & 1.8 & 1.0 & 2.0 & 1.8 & 1.0 \\
\hline Interest Rate & $12.89 \%$ & $2.98 \%$ & $12.92 \%$ & $12.91 \%$ & $2.96 \%$ & $12.92 \%$ & $12.92 \%$ & $2.97 \%$ & $12.92 \%$ \\
\hline Default Rate & $2.77 \%$ & $1.45 \%$ & $2.69 \%$ & $2.78 \%$ & $1.45 \%$ & $2.84 \%$ & $2.79 \%$ & $1.45 \%$ & $2.84 \%$ \\
\hline $\mathrm{E}(\mathrm{PV} \$ 1$ investment $)$ & 1.122 & 0.027 & 1.122 & 1.122 & 0.027 & 1.123 & 1.122 & 0.027 & 1.123 \\
\hline $\operatorname{Var}(\mathrm{PV} \$ 1$ investment $)$ & 0.036 & 0.020 & 0.035 & 0.027 & 0.020 & 0.022 & 0.036 & 0.020 & 0.035 \\
\hline \multicolumn{4}{|c|}{$\begin{array}{l}\text { B. Unit of observation: investor-month } \\
\qquad(\mathrm{N}=5,191)\end{array}$} & \multicolumn{3}{|c|}{$(\mathrm{N}=3,745)$} & \multicolumn{3}{|c|}{$(\mathrm{N}=3,145)$} \\
\hline Investment & 2,932 & 28,402 & 375 & 1,003 & 2,736 & 375 & 1,067 & 2,934 & 400 \\
\hline N Buckets & 9.7 & 8.7 & 7.0 & 11.7 & 8.4 & 10.0 & 11.8 & 8.5 & 10.0 \\
\hline N Projects & 18.8 & 28.0 & 8.0 & 23.3 & 28.9 & 14.0 & 23.8 & 29.5 & 14.0 \\
\hline $\mathrm{E}(\mathrm{PV} \$ 1$ investment $)$ & 1.121 & 0.023 & 1.121 & 1.121 & 0.021 & 1.121 & 1.121 & 0.021 & 1.121 \\
\hline $\operatorname{Var}(\mathrm{PV} \$ 1$ investment $)$ & 0.0122 & 0.0159 & 0.0054 & 0.0052 & 0.0065 & 0.0025 & 0.0066 & 0.0070 & 0.0038 \\
\hline
\end{tabular}

Each observation in panel A represents an investment allocation, with at least 2 risk buckets, by investor $\mathrm{i}$ in risk bucket $\mathrm{z}$ in month $\mathrm{t}$. In panel B, each observation represents a portfolio choice by investor i in month t. An investment constitutes a dollar amount allocation to projects (requested loans), classified in 35 risk buckets, within a calendar month. Loan requests are assigned to risk buckets according to the amount of the loan, the FICO score, and other borrower characteristics. Lending Club assigns and reports the interest rate and default probability for all projects in a bucket. The expectation and variance of the present value of $\$ 1$ investment in a risk bucket is calculated assuming a geometric distribution for the idiosyncratic monthly survival probability of the individual loans and independence across loans within a bucket. The sample in column 2 excludes portfolio choices in a single bucket and non-diversified investments. The sample in column 3 also excludes portfolio choices made by investors located in zip codes that are not covered by the Zillow Index.

Table 2: Descriptive Statistics 


\begin{tabular}{lcccc}
\hline & ARA & $\theta$ & $\begin{array}{c}\text { Expected } \\
\text { Income }\end{array}$ & $\begin{array}{c}\text { Income } \\
\text { Based RRA }\end{array}$ \\
\hline Mean & 0.03679 & 1.086 & 130.1 & 2.85 \\
sd & 0.02460 & 0.027 & 344.3 & 3.62 \\
p1 & -0.00837 & 1.045 & 4.11 & -0.16 \\
p10 & 0.01126 & 1.059 & 8.08 & 0.28 \\
p25 & 0.02271 & 1.075 & 16.0 & 0.56 \\
p50 & 0.04395 & 1.086 & 45.9 & 1.62 \\
p75 & 0.04812 & 1.094 & 111.1 & 3.66 \\
p90 & 0.05293 & 1.105 & 297.1 & 7.29 \\
p99 & 0.08562 & 1.157 & $1,255.1$ & 17.18 \\
N & 3,145 & 3,145 & 3,145 & 3,145 \\
\hline
\end{tabular}

Absolute Risk Aversion (ARA) and intercept $\theta$ obtained through the OLS estimation of the following relationship for each investment:

$$
E\left[R_{z}\right]=\theta^{i}+A R A^{i} \cdot \frac{W^{i} x_{z}^{i}}{n_{z}^{i}} \cdot \sigma_{z}^{2}+\xi_{z}^{i}
$$

where the left (right) hand side variable is expected return (idiosyncratic variance times the investment amount) of the investment in bucket z. The income based Relative Risk Aversion (RRA) is the estimated ARA times the total expected income from the investment in Lending Club. $p N$ represents the $N^{t h}$ percentile of the distribution.

Table 3: Unconditional distribution of estimated risk aversion parameters 


\begin{tabular}{ccccc}
\hline & ARA & $\theta$ & $\begin{array}{c}\text { Expected } \\
\text { Income }\end{array}$ & $\begin{array}{c}\text { Income } \\
\text { Based RRA }\end{array}$ \\
\hline $2007 \mathrm{~m} 10$ & 0.028 & 1.057 & 173.3 & 1.229 \\
& $(0.020)$ & $(0.014)$ & $(608.5)$ & $(0.980)$ \\
$2007 \mathrm{~m} 11$ & 0.032 & 1.065 & 111.3 & 1.195 \\
& $(0.018)$ & $(0.013)$ & $(337.6)$ & $(0.952)$ \\
$2007 \mathrm{~m} 12$ & 0.037 & 1.066 & 78.5 & 1.446 \\
& $(0.016)$ & $(0.013)$ & $(199.8)$ & $(1.527)$ \\
$2008 \mathrm{~m} 1$ & 0.036 & 1.083 & 175.9 & 2.774 \\
& $(0.031)$ & $(0.040)$ & $(522.8)$ & $(3.676)$ \\
$2008 \mathrm{~m} 2$ & 0.040 & 1.089 & 123.3 & 3.179 \\
& $(0.022)$ & $(0.018)$ & $(305.9)$ & $(3.906)$ \\
$2008 \mathrm{~m} 3$ & 0.037 & 1.097 & 146.4 & 3.841 \\
& $(0.025)$ & $(0.023)$ & $(288.0)$ & $(4.302)$ \\
$2008 \mathrm{~m} 4$ & 0.039 & 1.089 & 63.9 & 2.011 \\
& $(0.026)$ & $(0.023)$ & $(109.8)$ & $(2.275)$ \\
\hline
\end{tabular}

Absolute Risk Aversion (ARA) and intercept $\theta$ obtained through the OLS estimation of the following relationship for each investment:

$$
E\left[R_{z}\right]=\theta^{i}+A R A^{i} \cdot \frac{W^{i} x_{z}^{i}}{n_{z}^{i}} \cdot \sigma_{z}^{2}+\xi_{z}^{i}
$$

where the left (right) hand side variable is expected return (idiosyncratic variance times the investment amount) of the investment in bucket z. The income based Relative Risk Aversion (RRA) is the estimated ARA times the total expected income from the investment in Lending Club. Standard deviations in parenthesis.

Table 4: Mean risk aversion and systematic risk premium by month 


\begin{tabular}{|c|c|c|c|c|c|}
\hline \multicolumn{3}{|c|}{ ARA } & \multicolumn{3}{|c|}{$\theta$} \\
\hline $\begin{array}{c}\text { Automatic } \\
\text { (1) }\end{array}$ & $\begin{array}{c}\text { Non-Automatic } \\
(2)\end{array}$ & $\begin{array}{c}\Delta \\
(3)\end{array}$ & $\begin{array}{c}\text { Automatic } \\
(4)\end{array}$ & $\begin{array}{c}\text { Non-Automatic } \\
\text { (5) }\end{array}$ & $\begin{array}{c}\Delta \\
(6)\end{array}$ \\
\hline \multicolumn{6}{|c|}{ A. Full Sample $(n=227)$} \\
\hline $\begin{array}{c}0.0368 \\
(0.0215)\end{array}$ & $\begin{array}{c}0.0356 \\
(0.0194)\end{array}$ & $\begin{array}{l}-0.0012 \\
(0.0204)\end{array}$ & $\begin{array}{c}1.079 \\
(0.0209)\end{array}$ & $\begin{array}{c}1.080 \\
(0.0226)\end{array}$ & $\begin{array}{c}0.001 \\
(0.0213)\end{array}$ \\
\hline $\begin{array}{c}0.0355 \\
(0.0235)\end{array}$ & $\begin{array}{c}\text { B. Subsampl } \\
0.0340 \\
(0.0192)\end{array}$ & $\begin{array}{c}\text { Octobe } \\
-0.0016 \\
(0.0223)\end{array}$ & $\begin{array}{c}\text { ecember } 200 \\
1.062 \\
(0.0132)\end{array}$ & $\begin{array}{r}(\mathbf{n}=\mathbf{7 4}) \\
1.063 \\
(0.0193)\end{array}$ & $\begin{array}{c}0.001 \\
(0.0168)\end{array}$ \\
\hline $\begin{array}{c}0.0374 \\
(0.0206)\end{array}$ & $\begin{array}{l}\text { C. Subsam } \\
0.0364 \\
(0.0195)\end{array}$ & $\begin{array}{l}\text { e: Janua } \\
-0.0011 \\
(0.0195)\end{array}$ & $\begin{array}{c}\text { April } 2008 \\
1.087 \\
(0.0188)\end{array}$ & $\begin{array}{r}=\mathbf{1 5 3}) \\
1.089 \\
(0.0190)\end{array}$ & $\begin{array}{c}0.002 \\
(0.0232)\end{array}$ \\
\hline
\end{tabular}

Descriptive statistics of the Absolute Risk Aversion (ARA) and $\theta$ obtained as in Table 3, over the subsample of investments where the estimates can be obtained separately using Automatic (buckets suggested by optimization tool) and Non-Automatic (buckets chosen directly by investor) bucket choices for the same investment. The mean and standard deviation (in parenthesis) of both estimates and the difference for the same investment are shown for the full sample and for 2007 and 2008 separately. The mean differences are not significantly different from zero in any of the samples.

Table 5: Estimates from Automatic and Non-Automatic Buckets 


\begin{tabular}{|c|c|c|c|c|}
\hline $\begin{array}{l}\text { Dependent Variable: } \\
\text { (in } \operatorname{logs} \text { ) }\end{array}$ & $\begin{array}{l}\text { ARA } \\
(1)\end{array}$ & $\begin{array}{c}\text { Income based } \\
\text { RRA } \\
(2)\end{array}$ & $\begin{array}{l}\text { Investment } \\
\qquad(3)\end{array}$ & $\begin{array}{c}\text { First Stage } \\
\log (\text { Net Worth) } \\
(4)\end{array}$ \\
\hline $\begin{array}{l}\text { A. OLS } \\
\log (\text { Net Worth) }\end{array}$ & $\begin{array}{c}-0.009^{* *} \\
(0.004)\end{array}$ & $\begin{array}{c}0.022^{* * *} \\
(0.008)\end{array}$ & $\begin{array}{c}0.035^{* * *} \\
(0.009)\end{array}$ & \\
\hline $\begin{array}{l}\text { R-squared } \\
\text { Observations (investors) }\end{array}$ & $\begin{array}{l}0.003 \\
1,514\end{array}$ & $\begin{array}{l}0.005 \\
1,514\end{array}$ & $\begin{array}{l}0.010 \\
1,514\end{array}$ & \\
\hline $\begin{array}{l}\text { B. Errors-in-Variables } \\
\log (\text { Net Worth) }\end{array}$ & $\begin{array}{c}\text { (Instrum } \\
-0.059^{* * *} \\
(0.019)\end{array}$ & $\begin{array}{c}\text { at: House Val } \\
0.123^{* * *} \\
(0.031)\end{array}$ & $\begin{array}{l}0.203^{* * *} \\
(0.038)\end{array}$ & \\
\hline log (House Value) & & & & $\begin{array}{c}1.664^{* * *} \\
(0.146)\end{array}$ \\
\hline Observations (investors) & 1,261 & 1,261 & 1,261 & 1,261 \\
\hline
\end{tabular}

Estimated elasticity of risk aversion to wealth in the cross section. Panel A presents the OLS estimation of the between model and Panel B presents the errors-in-variables estimation using the median house value in the investor's zip code as an instrument for net worth. The dependent variables are the $(\log )$ absolute risk aversion (column 1), income-based relative risk aversion (column 2), and investment amount in LC (column 3), averaged for each investor $i$ across all portfolio choices in our sample. The right hand side variable is the investor (log) net worth (from Acxiom). Column 4 reports the first stage of the instrumental variable regression: the dependent variable is $(\log )$ net worth and the right hand side variable is the average $(\log )$ median house price in the investor's zip code (from Zillow). Standard errors are heteroskedasticity robust and clustered at the zip code level. ${ }^{*},{ }^{* *}$, and ${ }^{* * *}$ indicate significance at the $10 \%, 5 \%$, and $1 \%$ levels of confidence, respectively.

Table 6: Risk Aversion and Wealth, Cross Section Estimates 


\begin{tabular}{|c|c|c|c|}
\hline $\begin{array}{l}\text { Dependent Variable: } \\
\text { (in } \operatorname{logs} \text { ) }\end{array}$ & $\begin{array}{l}\text { ARA } \\
(1)\end{array}$ & $\begin{array}{c}\text { Income based } \\
\text { RRA } \\
(2)\end{array}$ & $\begin{array}{c}\text { Investment } \\
\text { (3) }\end{array}$ \\
\hline $\begin{array}{l}\text { A. No Fixed Effects } \\
\log \text { (House Value) }\end{array}$ & $\begin{array}{c}-0.166^{* * *} \\
(0.047)\end{array}$ & $\begin{array}{c}0.192^{* * *} \\
(0.048)\end{array}$ & $\begin{array}{c}0.367^{* * *} \\
(0.070)\end{array}$ \\
\hline $\begin{array}{l}\text { Risk Premium Controls } \\
\text { Investor Fixed Effects } \\
\text { R-squared } \\
\text { Observations } \\
\text { Investors }\end{array}$ & $\begin{array}{c}\text { Yes } \\
\text { No } \\
0.020 \\
2,030 \\
1,292\end{array}$ & $\begin{array}{c}\text { Yes } \\
\text { No } \\
0.010 \\
2,030 \\
1,292\end{array}$ & $\begin{array}{c}\text { Yes } \\
\text { No } \\
0.032 \\
2,030 \\
1,292\end{array}$ \\
\hline $\begin{array}{l}\text { B. Investor Fixed Eff } \\
\log \text { (House Value) }\end{array}$ & $\begin{array}{l}\text { cts } \\
\quad-2.825^{*} \\
(1.521)\end{array}$ & $\begin{array}{c}-4.815^{* * *} \\
(1.611)\end{array}$ & $\begin{array}{c}1.290 \\
(1.745)\end{array}$ \\
\hline $\begin{array}{l}\text { Risk Premium Controls } \\
\text { Investor Fixed Effects } \\
\text { R-squared (adj) } \\
\text { Observations } \\
\text { Investors }\end{array}$ & $\begin{array}{c}\text { Yes } \\
\text { Yes } \\
0.008 \\
2,030 \\
1,292\end{array}$ & $\begin{array}{c}\text { Yes } \\
\text { Yes } \\
0.011 \\
2,030 \\
1,292\end{array}$ & $\begin{array}{c}\text { Yes } \\
\text { Yes } \\
0.001 \\
2,030 \\
1,292\end{array}$ \\
\hline
\end{tabular}

Estimated investor-specific elasticity of risk aversion to wealth. The left hand side variables are the (log) absolute risk aversion (column 1), income-based relative risk aversion (column 2), and investment amount in LC (column 3), obtained for investor $i$ for a portfolio choice in month $t$. The right hand side variables are the (log) median house price in the investor's zip code in time $t$, and an investor fixed effect (omitted). Standard errors are heteroskedasticity robust and clustered at the zip code level. *, ${ }^{* *}$, and ${ }^{* * *}$ indicate significance at the $10 \%, 5 \%$, and $1 \%$ levels of confidence, respectively.

Table 7: Risk Aversion and Wealth Shocks, Investor-Specific Estimates 